TI 2018-096/VI

Tinbergen Institute Discussion Paper
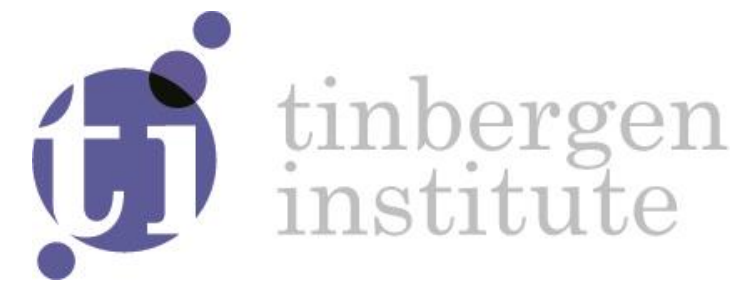

\title{
What Option Prices tell us about the ECB's Unconventional Monetary Policies
}

Stan Olijslagers ${ }^{1}$

Annelie Petersen ${ }^{2}$

Nander de Vette ${ }^{2}$

Sweder (S.J.G.) van Wijnbergen ${ }^{1,2,3}$

\footnotetext{
${ }^{1}$ UVA

2 DNB

${ }^{3}$ CEPR
} 
Tinbergen Institute is the graduate school and research institute in economics of Erasmus University Rotterdam, the University of Amsterdam and VU University Amsterdam.

Contact: discussionpapers@tinbergen.nl

More TI discussion papers can be downloaded at http://www.tinbergen.nl

Tinbergen Institute has two locations:

Tinbergen Institute Amsterdam

Gustav Mahlerplein 117

1082 MS Amsterdam

The Netherlands

Tel.: +31(0)205984580

Tinbergen Institute Rotterdam

Burg. Oudlaan 50

3062 PA Rotterdam

The Netherlands

Tel.: +31(0)10408 8900 


\title{
What Option Prices tell us about the ECB's Unconventional Monetary Policies*
}

\author{
Stan Olijslagers $^{\dagger} \quad$ Annelie Petersen ${ }^{\ddagger} \quad$ Nander de Vette ${ }^{\S}$ \\ Sweder van Wijnbergen
}

December 1, 2018

\begin{abstract}
We use a series of different approaches to extract information about crash risk from option prices for the Euro-Dollar exchange rate, with each step sharpening the focus on extracting more specific measures of crash risk around dates of ECB measures of Unconventional Monetary Policy. Several messages emerge from the analysis. Announcing policies in general terms without precisely describing what exactly they entail does not move asset markets or actually increases crash risk. Also, policies directly focused on changing relative asset supplies do seem to have an impact, while measures aiming at easing financing costs of commercial banks do not.
\end{abstract}

JEL codes: E44, E52, E58, E65, G12, G13, G14

Key Words: Quantitative Easing, Unconventional Monetary Policies, Exchange Rate Crash Risk, risk reversals, mixed diffusion jump risk models

\section{Introduction}

After the Lehman bankruptcy transformed a major but arguably manageable problem in American financial markets into a global financial crisis, Central Banks responded by massively providing liquidity to avoid a market collapse (Brunnermeier, 2009). Although the worldwide intervention managed to avoid a global meltdown, it could not prevent the beginning of what has turned out to become a very prolonged worldwide recession. Subsequent easing of monetary policy quickly ran into what until then had seemed a merely academic possibility, the Zero Lower Bound (ZLB) on interest rates. In response the major Central Banks resorted to Unconventional Monetary Policies (UMP), ranging from security market interventions to management by speech and specific measures to support distressed banks. There is a burgeoning literature on assessing the asset price impact of in particular the FED's intervention (see for example Krishnamurty and Vissing-Jorgenson (2011)), but there is much less known about the impact of the ECB's UMP measures. And there is very little empirical evidence on the extent to which Central Banks

\footnotetext{
${ }^{*}$ The views expressed in this paper are those of the authors and do not necessarily reflect the viewpoints of DNB. We thank Michel Vellekoop (UvA) and Christiaan Pattipeilohy (DNB) for helpful suggestions and comments.

†University of Amsterdam, s.w.j.olijslagers@uva.nl

$\ddagger$ DNB, A . petersen@dnb. nl

$\S$ DNB, N.j.de.vette@dnb.nl

IUniversity of Amsterdam, Tinbergen Institute, CEPR, s.j.g.vanwijnbergen@uva.nl
} 
succeeded in what arguably has been among their main objectives, calming the markets in the sense of reducing perceived crash risk.

Of course the ECB has no formal mandate to manage or otherwise influence the Euro-Dollar exchange rate, and has never declared it was attempting to influence that exchange rate, but the survival of the Euro has surely been one of its major concerns (vide ECB president Draghi's famous "Whatever it takes"-speech(Draghi, 2012) or Coeure (2017)). A crash of its value would have widely been seen as a precursor of the currency's eventual demise. Whether there was any unofficial targeting of the Euro-Dollar rate we do not know, nor whether that exchange rate played a role in the decision making process. But we take an explicitly more limited approach than looking at exchange rate impact in general; instead we focus explicitly on the extent to which unconventional ECB policy measures and announcements have reduced crash risk in the Euro-Dollar exchange rate ${ }^{1}$.

We can classify the large variety of UMP measures the ECB has taken into two groups. In ECB-speak, some target the ECB's Monetary Stance $(M S)$ and others target the Monetary Transmission Channel (MTC) given the Monetary Stance ${ }^{2}$. The classification does not quite fit our purpose since some measures fit in both categories. In our empirical work we employ a classification that matches the ECB terminology closely but where the categories are mutually exclusive, we distinguish measures aiming at the cost of funding of commercial banks and policies aiming at changing relative asset supplies (see Appendix A for a listing). Roughly speaking our null-hypothesis is that bank-directed measures should have no impact on crash risk and that policies aiming to change relative asset supplies should influence crash risk perceptions, hopefully in the right direction.

We use a series of different approaches to extract information about crash risk from option prices, with each step sharpening the focus on extracting specific measures of crash risk. We start by documenting changes in the skew of the empirical distribution underlying FX options derived from price data by considering so called risk reversals (see section 4.3 .3 for the definition). We present both graphic and econometric analysis documenting the impact of ECB UMP measures on skewness, where we attribute a reduction of skew as triggered by a decline in crash-related tail risk. Since these summary measures based on two points from the volatility surface seem promising, we then extract the entire (risk neutral) distribution from FX derivative contracts in a procedure based on the seminal work of Breeden and Litzenberger (1978) and associated numerical procedures outlined in Malz (2014) and present direct estimates of tail risk based on those procedures. Hattori, Schrimpf, and Sushko (2016) follow a similar procedure in their analysis of the impact of the Fed's UMP measures.

Using the entire volatility smile instead of using two (equal delta) implied volatilities yields sharper results by giving us a better measure of tailrisk. But a disadvantage of this procedure is that the numerical interpolation procedure used to derive the density function, through its smoothness requirements and endpoint clamping, does not allow for crash risks separate from the regular stochastic process driving the exchange rate in normal times. And yet that is obviously the type of crash risk Draghi had in mind in his famous "Whatever it takes"-speech(Draghi, 2012). To capture that sort of risk we take the analytical approach substantially beyond the procedures outlined in Malz (2014) and base our analysis on an explicit mixed jump-diffusion model driving the process underlying the derivative contracts analyzed and explicitly estimate the jump risk parameter from the option price data. We derive an explicit closed form solution to the resulting FX option pricing problem using the double exponential jump distribution introduced by Kou

\footnotetext{
${ }^{1}$ Although even if there was no official or unofficial targeting of exchange rates, UMP measures may still have had an impact on that exchange rate. Since such exchange rate effects of UMP are an interesting research topic, such effects may have played a role in the transmission process from UMP measures to the economy.

${ }^{2}$ We are indebted to Christiaan Pattipeilophy (DNB) for this introduction to the jargon the ECB uses.
} 
(2002). We calibrate the resulting model by using Non-linear Least Squares estimation to fit it to option price data surrounding the events we want to analyse for changes in jump probabilities.

A number of general messages emerge from the analysis. Announcing policies in general terms without precisely describing what exactly they entail does not move asset markets or even moves them in the wrong direction. And policies directly focused on changing relative asset supplies do seem to have an impact, while measures more generally aiming at easing financing costs of the commercial banks do not.

The remainder of this paper is organized as follows. In Section 2 we provide an overview of the ECB's UMP measures. Section 3 reviews related literature while Section 4 covers data and gives some useful definitions. Section 5 deals with methodology. There we first describe the event window regressions used in the first part of our analysis; we then present the analytical solution to the mixed diffusion-jump process option pricing model and explain the estimation procedures useed to calibrate the model and test for event related changes in its parameters (i.e. the methods used to estimate changes in crash risk probabilities). The results are presented and discussed in section 6 . Finally, section 7 concludes.

\section{Unconventional Monetary Policy Measures by the ECB}

Since the eruption of the global financial crisis (GFC) in 2007, central banks of hard-hit advanced economies dropped policy rates towards an effective zero lower bound until they could meaningfully ease no further using interest rate policy. However, market stress still remained high, whilst the main policy transmission tools had been exhausted. When the crisis progressed and intensified, special instruments and facilities were introduced for refinancing both banks and sovereigns under severe stress (Falagiarda \& Reitz, 2015). Early on in the crisis the ECB undertook steps in order to support the interbank money market in the euro area, among which:

i. Unrestricted liquidity provision through Fixed Rate Tenders with Full Allotment (FRTPFA), which allowed banks to get unlimited access to central bank liquidity at the main refinancing rate, contingent on proper collateral.

ii. Extension of the list of acceptable collateral assets for refinancing operations. (COLL)

iii. Extension of the maturity of Long-Term Refinancing Operations (LTRO) in order to remove uncertainty and enhance liquidity conditions for banks.

In May 2009 the ECB extended its operations to the covered bond market. The first Covered Bond Purchase Programme (CBPP1) involved the outright purchase of covered bonds and was complemented in November 2011 by CBPP2. Later on in the crisis the Governing Council announced the Securities Market Programme (SMP) which involved the direct purchase of unspecified amounts of euro area sovereign debt of distressed countries. While the SMP announcement stated that purchases might include both private and sovereign debt, only the latter has been purchased. SMP operations have been carried out in two big waves. During the first phase (May 2010-April 2011) the program consisted of purchases of Greek, Irish and Portuguese debt. Whereas the second wave entails the period from August 2011 until February 2012 after market perceptions concerning the creditworthiness of Italy and Spain deteriorated. In September 2012, the ECB discontinued the SMP and substituted it by the Outright Monetary Transactions (OMT) program whereby the ECB would intervene for unspecified and unrestrained amounts in secondary sovereign-bond markets if the Governing Council would consider that redenomination risk was impairing Monetary Transmission to an unacceptable degree. The countries affected would have to agree to an economic reform programme (conditionality principle) as a necessary precondition for an OMT intervention. The OMT has never been tested but was introduced with great publicity by ECB president Mario Draghi in his speech with the by now famous line: 
"Within our mandate, the ECB is ready to do whatever it takes to preserve the euro. And believe me, it will be enough."(Draghi, 2012)

In a way the OMT was communication without intervention, contrary to the SMP, which mainly entailed intervention with little transparent communication. By announcing two longerterm refinancing operations in December 2011, the ECB decided to complement the Eurosystem's regular open market operations, also known as the Main Refinancing Operations (MRO), which mainly served to both steer short-term interest rates and signal the monetary policy stance, along with the management of liquidity (ECB, 2016). Banks hereby obtained full allotment loans against a variety of collateral, with a collateral-specific haircut schedule.

In July 2013 the ECB embraced forward guidance (FWG) as a new monetary communication strategy order to avoid surprises that might disrupt financial markets. When all this deemed insufficient, the ECB announced additional measures in the form of a Credit Easing Package (CEP) based on two pillars:

(i) a series of targeted longer-term refinancing operations (TLTRO) designed to enhance bank lending to the non-financial private sector of the euro area;

(ii) outright purchases of asset-backed securities (ABSPP) in parallel with a new covered bond purchase programme (CBPP3).

Against the threat of deflation, the ECB adopted in January 2015 the Asset Purchase Programme (APP), which complemented the private sector programmes (CBPP3 and ABSPP) by a purchase programme for public sector securities (PSPP). In particular, under the PSPP the ECB purchased sovereign bonds of euro area countries based on their respective share in the capital key to restore the transmission mechanism of monetary policy and curb soaring risk premia. In June 2016 the Eurosystem started to buy corporate sector bonds under the corporate sector purchase programme (CSPP) which aimed at further strengthening the pass-through of the Eurosystem's asset purchases to financing conditions of the real economy.

Even before the start of the APP, the Governing Council decided to cut the interest rate on the deposit facility with 10 basis points (bps) into negative territory for the first time in history. Every policy rate cut hereafter contains 10 basis points (bps) as opposed to earlier policy rate decisions which entailed steps of $25 \mathrm{bps}$. The lowering of the deposit facility rate stopped at the level of $-0.4 \%$. A glossary of all program abbreviations is given in Appendix A.

\section{Related Literature}

Since the ECB embraced these unconventional monetary policy (UMP) actions, there has been a growing body of empirical literature to analyse its transmission mechanisms. The focus has been on four different channels: the exchange rate channel, signaling, portfolio-rebalancing and market functioning (De Pooter, Rebecca, Martin, \& Pruitt, 2015; Falagiarda \& Reitz, 2015; Hattori et al., 2016):

I. The exchange rate channel is assumed to be the key transmission channel within the euro area (Georgiadis \& Gräb, 2016). The exchange rate is one of the intermediate policy variables through which monetary policy is transmitted to the larger economy. Lower interest rates as a result of asset purchase programs weaken the domestic currency (i.e. depreciating euro) which in turn makes exports become cheaper to foreign buyers, thereby inducing higher competition in export markets at home.

II. Via the signaling channel central bank announcements can signal commitment to monetary stimulus, which subsequently will lower the expected path of future short-term rates. Through this channel the central bank enhances the credibility of policy rates staying low for long. This channel is closely related to the forward guidance communication strategies, particularly through 
the ECB's earlier communicated commitment of "keeping key interest rates to remain at their present levels for an extended period of time, and well past the horizon of our net asset purchases". This channel emphasizes the role of private agents' expectations of future economic conditions and policy actions.

III. In the portfolio-rebalancing channel central banks influence yields by influencing the relative supplies of assets with different maturities. This channel emphasizes the imperfect substitutability among different assets (i.e. assets are not perceived as perfect substitutes by investors) and reflects a degree of market segmentation. Moreover, agents are heterogeneous and hold different portfolios. Consequently, purchases carried out by the central bank will entail a rebalancing of investors' portfolios. This is, investors with preferences for certain bonds with specific maturities or safety characteristics (i.e. preferred habitat investors) switch to close substitutes of the purchased securities.

IV. Another important channel of UMP is the liquidity premia channel, also referred to as the market functioning channel. In times of financial panic, markets usually are characterized by poor market liquidity and therefore assets contain a higher risk premium. The presence of a central bank acting as a protagonist in financial markets could substantially enhance market liquidity which therefore leads to lower risk premiums. This new role of the central bank might make investors more willing to behave actively in markets, knowing that they could sell the financial products to the monetary authority if necessary.

Clearly transmission channels are not mutually exclusive and can work in parallel (Fratzscher, Duca, \& Straub, 2014). More recent work has looked at the broader transmission of monetary policy to other assets and markets via their impact on risk perceptions and financial sector risk-taking (Hattori et al., 2016).

The exchange rate channel has been widely recognized as one of the main transmission channel of the APP - reinforced by negative rate policies (Arteta, Kose, Stocker, \& Taskin, 2018). In this study we focus on that channel and specifically on the impact of unconventional policies on perceptions of tail risk in Euro-Dollar options. In a way this study will test the transmission mechanism of Brunnermeier, Sannikov, et al. (2012) who suggest that central bank purchases can serve as insurance against tail events in combination with clear communication and commitment. In their model the central bank can signal its commitment to redistribute tail risk, which can have an immediate effect on market expectations and pricing of downside risks. This choice of focus also follows the views of the ECB's Mario Draghi: "The main aim of the OMT is to remove tail risk to overcome monetary and financial fragmentation of the euro area that would stem from a redenomination risk. And we would do it in a size that would be adequate to achieve its objective." (Draghi, 2012)

\section{Data and Some Definitions}

\subsection{Data}

The data is retrieved from Bloomberg. The conventions for quoting prices in the FX options market are different from other markets. For a given maturity, Bloomberg provides the at-themoney (ATM), risk reversal (RR) and butterfly (BF) quotes for different deltas ${ }^{3}$. In order to apply both the RNPD and Non-linear Least Squares, we need option prices for different strike prices. These are not directly available in Bloomberg but can be calculated from the data Bloomberg does provide.

\footnotetext{
${ }^{3}$ See 4.3 .3 and 4.3 .4 below for a definition of RR and BF.
} 
There are different conventions for how to define deltas, ATM and RR. Reiswich and Wystup (2010) give a detailed summary of the different FX quoting conventions. We will briefly discuss the different conventions that are used and which ones apply to the EUR/USD exchange rate.

\subsection{FX option pricing under Black Scholes}

The pricing formula for FX options was first proposed by Garman and Kohlhagen (1983) but is closely related to the option pricing formula derived by Black and Scholes $(1973)^{4}$. We use the following notation:

$$
\begin{aligned}
& S_{t}=\text { spot exchange rate at time } \mathrm{t}(€ / \$) \\
& K=\text { strike price } \\
& \tau=\text { time to maturity } \\
& r_{\$}=\text { domestic interest rate }(\$) \\
& r_{€}=\text { foreign interest rate }(€) \\
& \mu=\text { drift of the spot rate } \\
& \sigma=\text { volatility of the spot rate } \\
& \Phi(.)=\text { Standard normal CDF }
\end{aligned}
$$

Furthermore, the usual assumptions apply: Markets are frictionless (no transaction costs), interest rates are constant and the spot rate follows a Geometric Brownian Motion (GBM):

$$
d S_{t}=\mu S_{t} d t+\sigma S_{t} d W_{t}
$$

Then the price of a European FX call-option is given by:

$$
C^{\mathrm{BS}}\left(S, \tau ; K, r_{\$}, r_{€}, \sigma^{2}\right)=e^{-r_{€} \tau} C\left(S, \tau ; K, r_{\$}-r_{€}, \sigma^{2}\right)
$$

Here $C($.$) is the usual Black-Scholes option pricing formula. Using Put-Call parity, the price of$ a put option can then be derived from:

$$
C^{\mathrm{BS}}\left(S, \tau ; K, r_{\$}, r_{€}, \sigma^{2}\right)+K e^{-r_{€} \tau}=P^{\mathrm{BS}}\left(S, \tau ; K, r_{\$}, r_{€}, \sigma^{2}\right)+S e^{-r_{\$} \tau}
$$

\subsection{Some basic definitions}

\subsubsection{Delta}

Let us start with the delta of an option. The delta indicates the sensitivity of the value of the option to the price of the underlying. The delta is commonly defined as the spot delta or the forward delta. The spot delta is used used for a hedge in the spot market whereas the forward delta is used to gedhe in the forward market. Hedging in the forward market also takes interest rate risk into consideration. Therefore, the forward delta is used for longer maturities ( $>1$ year) or for emerging markets (since there the interest differentials are often large). In this paper we look at maturities shorter than one year and therefore we use spot deltas. Second, the delta can be either regular or premium-adjusted, depending on whether the premium is paid in domestic or foreign currency. For the EUR/USD pair, regular deltas are used and therefore we do not discuss the premium-adjusted deltas.

The delta of a call option can then be calculated as follows:

\footnotetext{
${ }^{4}$ The only difference is that the foreign interest rate enters the formula when considering FX options instead of stock options.
} 


$$
\begin{aligned}
& \delta^{C}=C_{s}=\frac{\partial}{\partial S} C^{\mathrm{BS}}\left(S, \tau ; K, r_{\S}, r_{€}, \sigma^{2}\right)=e^{-r_{€} \tau} \Phi\left(d_{1}\right) \\
& d_{1}=\frac{\ln \left(\frac{S}{K}\right)+\left(r_{\$}-r_{€}+\frac{\sigma^{2}}{2}\right) \tau}{\sigma \sqrt{\tau}}
\end{aligned}
$$

By rewriting (4) we can obtain $K$ as function of $\delta$ :

$$
K=S \exp \left(\left(r_{\$}-r_{€}+\frac{\sigma^{2}}{2}\right) \tau-\sigma \sqrt{\tau} \Phi^{-1}\left(e^{r_{€} \tau} \delta\right)\right)
$$

Lastly, we can calculate the delta of a put option, $\delta^{P}$, using the Put-Call delta parity:

$$
\delta^{C}+\delta^{P}=\frac{\partial}{\partial S} C^{\mathrm{BS}}\left(S, \tau ; K, r_{\$}, r_{€}, \sigma^{2}\right)+\frac{\partial}{\partial S} P^{\mathrm{BS}}\left(S, \tau ; K, r_{\S}, r_{€}, \sigma^{2}\right)=e^{-r_{€} \tau}
$$

\subsubsection{ATM}

In the FX markets, there are different ways to define ATM. ATM can be defined as: (i) an option with strike equal to the underlying $(S=K)$, (ii) an option with strike equal to the outright forward rate with similar time to maturity $\left(f=K\right.$ with $\left.f=S e^{\left(r_{\epsilon}-r_{\S}\right) \tau}\right)$, (iii) an option with strike such that a straddle has zero net delta. A straddle is a combination of a long call and a long put with the same strike and maturity. Bloomberg uses the last ATM definition. We can then derive the strike corresponding to this definition.

First, from (4) and (6) we find that the delta of a put option equals:

$$
\delta^{P}=-e^{-r_{\epsilon} \tau} \Phi\left(-d_{1}\right)
$$

Then solving $\delta^{C}=\delta^{P}$ is equivalent to solving $d_{1}=0$. This gives:

$$
K=S \exp \left(\left(r_{\$}-r_{€}+\frac{\sigma^{2}}{2}\right) \tau\right)
$$

\subsubsection{Risk reversal}

Our dataset contains the ingredients to contstruct a risk reversals for three deltas $(\delta=0.1,0.25,0.35)$. The risk reversal is defined as the difference between the out-of-the-money (OTM) call and put implied volatility's at the same $\delta$. It measures the skewness of the implied volatility distribution. When the risk reversal is negative, the implied volatility of an OTM put option is larger than for a call option with the same $\delta$. The risk reversal for a given $\delta$ equals:

$$
\mathrm{RR}_{\delta}=\sigma_{\delta}^{C}-\sigma_{\delta}^{P}
$$

In the risk reversal regressions below we actually work with a normalized RR variable by normalizing $R R_{\delta}$ by the implicit At-The-Money (ATM) voilatility:

$$
R R_{\delta}^{n}=\left(\sigma_{\delta}^{C}-\sigma_{\delta}^{P}\right) / \sigma_{A T M}
$$




\subsubsection{Butterfly}

Furthermore, the dataset contains butterflies for the same three deltas. The butterfly is defined as the average of the volatility of an OTM call and put option with the same delta less the ATM volatility. It measures the convexity of the volatility smile. For a given $\delta$, the butterfly equals:

$$
\mathrm{BF}_{\delta}=\frac{\sigma_{\delta}^{C}+\sigma_{\delta}^{P}}{2}-\sigma_{\mathrm{ATM}}
$$

\subsubsection{Call option prices}

Combining all this information, we can calculate the call option prices for seven different strikes. First, we can obtain seven $(\sigma, K)$ pairs and then, using the BS-formula we obtain the corresponding call option prices.

The ATM pair is straightforward. We obtain $\sigma_{\mathrm{ATM}}$ from Bloomberg and calculate the corresponding strike from (8). For each $\delta$, we can calculate the implied volatility for an OTM call and put option using the risk reversal and butterfly. From (9) and (11) we obtain:

$$
\sigma_{\delta}^{P}=\sigma_{\mathrm{ATM}}+\mathrm{BF}_{\delta}-\frac{\mathrm{RR}_{\delta}}{2}, \quad \sigma_{\delta}^{C}=\sigma_{\delta}^{P}+\mathrm{RR}_{\delta}
$$

This gives us the implied volatilities of three OTM call options and three OTM put options. We can transform the OTM put options to in-the-money (ITM) call options. Using the Put-Call delta parity (6) we obtain the deltas that correspond to the ITM call options. Lastly, we can use (5) to calculate the strikes that match the deltas.

\section{$5 \quad$ Methodology}

We first discuss the procedures we used to extract the Risk Neutral Probability Distribution (RNPD) from option prices and explain the event window regression setup. In the second part of this section we give the analytical solution to the option pricing model when the underlying follows a jump-diffusion process using exponential distributions for the jump risk part; we then present the two different estimation procedures we use to specifically extract and test for (changes in) jump risk.

\subsection{Part 1: Risk reversals and RNPD}

\subsubsection{Derivation procedure of implied distributions and RNPD based crash risk probabilities}

The RNPD is constructed using Euro-Dollar option prices from Bloomberg. The sample consists of data starting in January 2009 an ending in January 2018 and covers option deltas from 10 until 90, hence also covers fairly extreme market states. For European call options at time zero with the underlying spot price of the asset $S$ with expiration at $T$ and strike $K$ the RNPD is related to the call price: Breeden and Litzenberger (1978) show that the RNPD of the underlying equals the second derivative of the call price function with respect to the strike price.

Instead of approximating the call price function directly, Shinko (1993) recommends fitting the volatility smile through the Implied Volatility points across a universe of strike prices since this procedure reduces the sensitivity of the eventual RNPD to estimation errors. However the Bloomberg data we use is not quoted in strike-volatility space, but in delta-volatility space. Note that the exercise price of a currency option can be expressed in terms of the Black-Scholes 
delta, since $\delta$ equals the first derivative of the Black-Scholes option value with respect to its price. Therefore, the volatility surface of currency options can be seen as a function $\sigma(t, \delta, \tau)$ (the current date, delta and the time to expiry), instead of as a function of the date, strike and time to expiry. In a first step we therefore interpolate the volatilty smile in delta-volatility space. This is done by fitting a clamped cubic spline through the data points. However, we need the call price as a function in K-space to derive the RNPD so the volatilities in delta space need to be transformed into volatilities in strike space. We can then transform the fitted smile into a fitted call price function, from which the RNPD can be derived following Breeden and Litzenberger (1978). However, Bliss and Panigirtzoglou (2004) point out that it is not possible to map directly between the option delta and the underlying strike price of the option, since the implied volatility varies with both the strike and the delta itself. Instead one can transform any $K$ into a corresponding $\delta_{K}$ using (4) with $\sigma=\sigma_{A T M}{ }^{5}$. The fitted implied volatility $\sigma_{K}$ can then be evaluated at $\delta_{K}$ using the spline function $g_{i}(\delta)$ corresonding to the interval $(\mathrm{i}, \mathrm{i}+1)$ in which $\delta_{K}$ falls. In the last step, the call price $C^{B S}($.$) can be calculated using (2) and inserting$ both $K$ and $\sigma_{K}$. The density function can then be derived by numerically evaluating its second derivative with respect to the strike price $\mathrm{K}^{6}$.

\subsubsection{Event window regression setup}

For the first part of the analysis we examine the option implied risk reversal and the RNPD for the main ECB unconventional monetary policy announcements (SMP, OMT, PSPP, refinancing operations and negative interest rate policy (NIRP) where the deposit facility rate enters belowzero territory). We use options on the Euro-Dollar to assess whether or not the perceptions of crash risk in the exchange rate reacted on UMP announcements. The empirical analysis for the risk-reversal is similar to the event study methodology of Hattori et al (2016) and is based on the following regression:

$$
\Delta 10 \delta_{t}^{\tau}=\beta \theta_{t}+C i t i_{t}+\varepsilon_{t}
$$

where $\Delta 10 \delta_{t}^{\tau}$ refers to the $10 \delta$ risk reversal. $\Delta$ is the the log difference operator. $\theta_{t}$ is a dummy equaling one in the 3 days surrounding the announcement (event window) and zero otherwise. The event window $(T=3)$ is chosen because option markets - although liquid - need some time to digest new information in full. The control variables include contemporaneous macroeconomic data surprises captured by the log difference in the rescaled value of the Citigroup Economic Surprise Index. The Citigroup Index is calculated as the normalized deviation between the actual data release and the market consensus prior to the release and thus captures economic suprises that could interfere with the results.

In the part of the analysis where we use explicit tail probabilities $F_{t}(x)$ derived from the RNPD, we use a similar regression, with the tail probability as dependent variable instead of the risk-reversal.

\subsection{Part 2: Estimation procedures to extract crash risk probabilities.}

\subsubsection{Option pricing with jump risk}

In order to apply the estimation methods we turn to below, we first need some definitions and option pricing formulas when the underlying follows a jump-diffusion process.

\footnotetext{
${ }^{5}$ See Bu and Hadri (2007) for several reasons why the ATM volatility should be used instead of the implied volatilities at the different strike price points.

${ }^{6}$ Numerical differentiaton requires using a similar procedure to obtain $C(K \pm h)$.
} 
As is well known, several assumptions of the Black-Scholes model are violated in reality. Bates (1996) proposes to use a model for FX option pricing that incorporates stochastic volatility and jump risk. The model is justified by several empirical observations. ${ }^{7}$ First, the distribution of spot rate increments, $\ln \left(\frac{S_{t+\Delta}}{S_{t}}\right)$, is not normally distributed, but is be leptokurtic. In other words, the distribution has a higher peak and heavier tails compared to the normal distribution. Besides, volatility is not constant over time, but is time-varying. Lastly, the Black-Scholes model cannot explain the volatility smile. The volatility smile refers to the implied volatility pattern for different strike prices. Further ITM and OTM options have a higher implied volatility compared to ATM options. The leptokurtic distribution and the volatility smile can be explained by both stochastic volatility and jump risk models.

In this paper we will only focus on incorporating jump risk. We do not incorporate stochastic volatility, since it turns out to be very hard to distinguish between stochastic volatility and jump risk when calibrating the implied distribution. Conceptually, it is also more interesting to look at jump risk since we are interested in whether the ECB announcements reduce the risk on a crash of the Euro.

Let us now assume that instead of a GBM, the spot rate follows a jump-diffusion process:

$$
d S_{t}=(\mu-\lambda E(V-1)) S_{t} d t+\sigma S_{t} d W_{t}+(V-1) S_{t-} d N_{t}
$$

Here $S_{t-}=\lim _{h \downarrow 0} S_{t-h}, N_{t}$ is a Poisson process with arrival rate $\lambda$ and $V$ is a random variable with probability distribution function $f_{V}(v) . V-1$ can be seen as the percentage change of the spot rate after a jump and should be bounded between $(-1, \infty)$ such that the exchange rate can never be negative.

\subsubsection{The Kou model}

For the jump part of the process we use the double exponential distribution introduced by Kou (2002), for a number of reasons. First, the model leads to an analytic option pricing formula. Moreover, the exponential distribution of the model has thick tails and is therefore often used to model tail risk. Lastly, with some additional assumptions, we are able to reduce the number of estimation parameters. This will be explained later in this section, after the pricing formula is introduced. As a robustness check, we will also perform our analysis using the Merton jump diffusion model in Appendix C.1. The Merton model also has an analytic option pricing formula. However, it has one extra degree of freedom, the jump volatility in the Merton model has to be estimated separately from the expected jump size. This makes the model more flexible and leads to better fits compared to the Kou model, but also increases the chance of overfitting. The possible overfitting of the Merton model is the main reason that we use the Kou model as main model.

Kou (2002) proposes to use a double-exponential distribution to model the jump size distribution. Define $V=e^{Y}$, where $Y$ has the following probability density function (pdf): $f_{Y}(y)=p \eta_{1} e^{-\eta_{1} y} \mathbb{1}_{y \geq 0}+(1-p) \eta_{2} e^{\eta_{2} y} \mathbb{1}_{y<0}, \eta_{1}>1, \eta_{2}>0$. Here $p$ is the probability of an upward jump and $1-p$ the probability of a downward jump. $\eta_{1}$ and $\eta_{2}$ are the parameters corresponding to respectively an upward and a downward jump. $E(V)=p \frac{\eta_{1}}{\eta_{1}-1}+(1-p) \frac{\eta_{2}}{\eta_{2}+1}$. Let $\lambda^{*}, \eta_{1}^{*}, \eta_{2}^{*}$ be the risk-neutral parameters. The price of a European option becomes ${ }^{8}$ :

\footnotetext{
${ }^{7}$ See Bates (1996) for an overview of the empirical literature on exchange rates, this is beyond the scope of this paper.

${ }^{8}$ The formula is slightly adjusted for the exchange rate option, since we have both a domestic and foreign interest rate in the option formula.
} 


$$
\begin{aligned}
& C^{\mathrm{Kou}}\left(S, \tau ; K, r_{\$}, r_{€}, \sigma, \lambda^{*}, p, \eta_{1}^{*}, \eta_{2}^{*}\right)= \\
& S e^{-r_{€} \tau} \Upsilon\left(\ln \left(\frac{K}{S}\right), \tau ; r_{\$}-r_{€}+\frac{1}{2} \sigma^{2}-\lambda^{*} \zeta^{*}, \sigma, \lambda^{*}\left(\zeta^{*}+1\right), \frac{p}{1+\zeta^{*}} \frac{\eta_{1}^{*}}{\eta_{1}^{*}-1}, \eta_{1}^{*}-1, \eta_{2}^{*}+1\right) \\
& -K e^{-r_{\$} \tau} \Upsilon\left(\ln \left(\frac{K}{S}\right), \tau ; r_{\$}-r_{€}-\frac{1}{2} \sigma^{2}-\lambda^{*} \zeta^{*}, \sigma, \lambda^{*}, p, \eta_{1}^{*}, \eta_{2}^{*}\right)
\end{aligned}
$$

where

$$
\zeta^{*}=p \frac{\eta_{1}^{*}}{\eta_{1}^{*}-1}+(1-p) \frac{\eta_{2}^{*}}{\eta_{2}^{*}+1}-1
$$

The $\Upsilon($.$) function is defined in Kou (2002).$

We make two simplifying assumptions, both stemming from the context within which this machinery is being applied. The first assumption is that we assume that in the Kou model, only downward jumps can take place. After all we want to know whether the ECB's UMP actions (and announcements of its future actions), managed to influence the perception of an impending Euro crisis. An upward jump has no place in such a setting. This means that we set the probability of an upward jump $(p)$ equal to zero. This reduces the set of estimation parameters to three for the Kou model: $\left(\sigma, \lambda^{*}, \eta_{2}^{*}\right)$.

Second, we assume that only one jump can take place during the duration of an option. It is not plausible that the Euro will crash more than once within a period of six months. This assumption makes it easier to interpret the arrival rate $\lambda$, since we can just transform it into a probability on a jump occurring within a certain time period. This translates into the option pricing formula as follows: instead of having an infinite sum within the $\Upsilon$ (.) function (Kou, 2002), we only sum up to and including $n=1$. The probability of having no jumps remains $\exp \left(-\lambda^{*} \tau\right)$. The probability of one jump $(n=1)$ changes from $\exp \left(-\lambda^{*} \tau\right) \lambda^{*} \tau$ to $1-\exp \left(-\lambda^{*} \tau\right)$.

\subsection{Estimation}

We want to obtain the distribution implied in the FX option prices. Define the parameter vector of the Kou model by $\theta=\left[\begin{array}{lll}\sigma & \lambda^{*} & \eta_{2}^{*}\end{array}\right]$. Assume we want to calibrate our parameters on a set of options with $n$ maturities, $m$ strike prices and $T$ days. Then we obtain the implied parameters by minimizing the error between the theoretical price of an option and the observed market price $C^{*}$.

$$
\theta=\arg \min \sum_{i=1}^{n} \sum_{j=1}^{m} \sum_{t=1}^{T} \omega_{i, j, t}\left[C^{K o u}\left(S_{t}, \tau_{i}, K_{i, j, t} \mid \theta\right)-C^{*}\left(S, \tau_{i}, K_{i, j, t}\right)\right]^{2}
$$

$\omega_{i, j, t}$ are weights that determine the relative importance of the different observations. We want to give more liquid options a higher weight since more liquid prices are more reliable. In order to do so, we could define $\omega_{i, j, t}=\frac{1}{|b i d-a s k|}$, where the bid-ask spread determines the liquidity of an option. However, bid-ask spreads are not available in our case.

It is possible calibrate our models using implied volatility's instead of option prices. This gives errors proportional to bid-ask spreads (Cont \& Tankov, 2002). However, this requires an inversion of the Black-Scholes formula in every step of the estimation and is therefore costly in terms of computation time. Following Cont and Tankov (2002) we use that minimizing the errors using implied volatilities is approximately equal to minimizing the errors using option prices with weights equal to: $\omega_{i, j, t}=\frac{1}{V e g a_{i, j, t}^{2}}$. Here Vega equals the Black-Scholes Vega (first derivative 
with respect to the volatility): $\operatorname{Vega}_{i, j, t}=S \phi\left(d_{1}\right) \sqrt{\tau}$ where $\phi($.$) is the standard-normal pdf. The$ weights are normalized to sum up to one.

\subsection{Identification problem}

It turns out to be very hard to distinguish between diffusion risk and jump risk. We illustrate this identification problem using an example. The data for this example consists of seven call option prices with 6 month maturity from January 2, 2015. (16) is minimized using a solver (fmincon in Matlab) that locates the local minimum of a function ${ }^{9}$. The estimation yields the following parameter vector: $\theta=\left[\begin{array}{lll}\sigma & \lambda^{*} & \eta_{2}^{*}\end{array}\right]=\left[\begin{array}{lll}0.080 & 0.207 & 9.97\end{array}\right]$. Figure 1 below shows that the model can quite accurately produce the volatility smile that is observed in the market.

Figure 1: Volatility smile of the Kou model

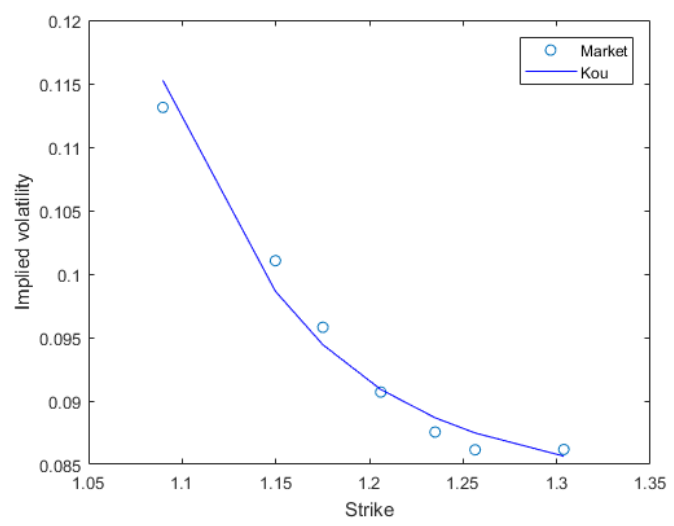

Implied volatility smile observed in market (blue dots) and the smile generated by the calibrated Kou model.

Figure 2 is obtained by varying $\sigma$ and $\lambda$ after the estimation, leaving the other parameters equal to their calibrated value. It can be seen that the error function is not very convex (almost a flat line). This implies that several parameter combinations can give a good fit. The outcome of the estimation can depend on the starting point of the optimization problem. Especially the contour plot shows that there can be multiple local minima. Increasing the sample of options does not solve this problem.

To tackle the identification problem between diffusion risk and jump risk, we choose to fix the volatility $\sigma$ before the estimation based on time series information from before the crisis, when perceptions of an impending crisis were small or non-existent. We can use time series data for estimation of the volatility, since the volatility is the same under the risk neutral measure (Girsanov theorem, see Shreve (2004) Ch. 5.2). If we assume that before the crisis there was no jump risk for the Euro-Dollar exchange rate, we can accurately estimate the volatility from time series data. Based on daily data from 2-1-2002 until 29-12-2006 (5 years) we estimate that the average annualized volatility equals $.0922^{10}$. During and after the crisis, there can be additional crash risk that is priced in option prices. By fixing the volatility at the pre-crisis level, we implicitly assume that all additional risk will be jump risk. We try to extract this risk from

\footnotetext{
${ }^{9}$ Initial parameters (starting point for optimization) equal: $\theta_{0}=\left[\begin{array}{lll}0.08 & 0.5 & 10\end{array}\right]$.

${ }^{10}$ Data is obtained from the ECB (https://sdw.ecb.europa.eu/quickview.do?SERIES_KEY=120.EXR.D.USD.EUR .SP00.A). The estimation is based on 255 trading days per year.
} 
Figure 2: Estimation errors
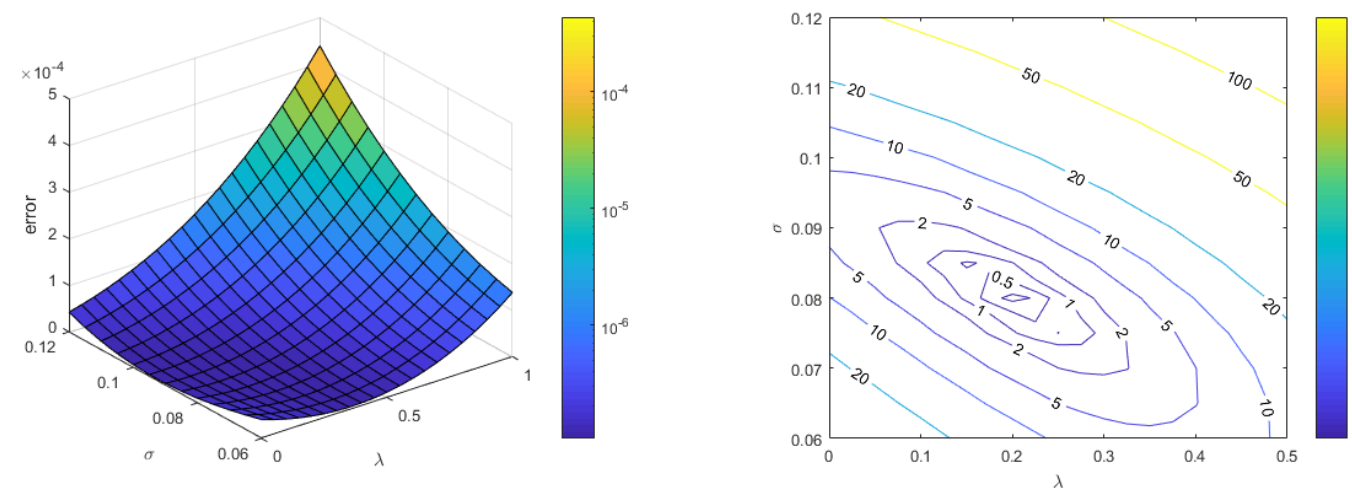

After the estimation, the volatility $\sigma$ and jump arrival rate $\lambda$ are varied to illustrate the identification problem. Left: 3D figure with the estimation errors for different values of $\sigma$ and $\lambda$. Right: Contour plot with estimation errors $\left(* 10^{-6}\right)$.

post-crisis option prices and use the results to find out whether the ECB policy announcements have effectively reduced the risk on a crash of the Euro.

However, there is a similar identification problem between the arrival rate and the jump size. A jump distribution with twice the probability on a jump but half the jump size is very hard to distinguish from the initial distribution. Again, several distributions can accurately fit the data. Let us consider a simple example. Assume we perform an estimation before and after an event and we would like to find out whether the event has influenced the implied distribution. The estimation just before the event yields a jump probability of $10 \%$ and an expected jump size of $-10 \%$. However, there is another local minimum which has an error that is slightly larger with jump probability $5 \%$ and jump size $-20 \%$. We want to calibrate the distribution implied in option prices just before and just after the event. Now it can happen that with only a slight change in option prices, the other local minimum is selected in the estimation after the event. Then our conclusion might be that the event has a large influence on the implied distributions since the jump probability is halved and the expected jump size has doubled. However, the underlying option prices have hardly changed. To tackle this problem, we use two methods, Regularization and Joint Estimation. We discuss each in turn.

\subsection{Regularization}

Cont and Tankov (2002) discuss the identification problem and propose a regularization method to tackle it. Instead of solving the estimation problem in (16), they propose to solve:

$$
\theta=\arg \min \sum_{i=1}^{n} \sum_{j=1}^{m} \sum_{t=1}^{T} \omega_{i, j, t}\left[C^{K o u}\left(S_{t}, \tau_{i}, K_{i, j, t} \mid \theta\right)-C^{*}\left(S_{t}, \tau_{i}, K_{i, j, t}\right)\right]^{2}+\alpha H(\theta)
$$

where $H(\theta)$ denotes the relative entropy between a pre-specified prior model and the model with parameter $\theta$. Relative entropy measures the distance between two probability measures. The extra penalty term makes the error function convex. $\alpha$ determines the relative importance between the minimization of the errors and the penalty term. The result is that the optimization outcome is not dependent anymore on the starting point of the optimization. This method gives 
up accuracy in order to make the estimation stable. Cont and Tankov (2002) propose a nonparametric estimation of the jump risk density, but this might also lead to over-specification and is less tractable. Therefore we apply this method to a parametric estimation. This approach can also be given an ambiguity aversion interpretation where pdf's differ from a preferred one are incorporated in the objective function with a penalty attached (Anderson, Hansen, \& Sargent, 2000).

We apply the regularization method to our problem as follows: Assume we want to find out what the effect of an ECB announcement was on the implied distribution. We first calibrate the model without regularization on data of three trading days before the event using options with one, three and six month maturities. For each maturity we have seven call prices. This gives us 63 observations per estimation $(3 \times 3 \times 7)$. Then we solve (16) to find a vector of parameters.

We cannot just use the solver with any starting point, since there might be multiple local minima. In order to find the global minimum, we first use random search to find a point with the lowest error ${ }^{11}$. Then we use that point as starting point and use the Matlab function fmincon to find the minimum. $\lambda^{*}$ and $\eta_{2}^{*}$ should both be positive, furthermore we only look at jump sizes larger or equal to $-5 \%$. We want to capture crash risk with the jump distribution and changes of one or two percent are already captured by the diffusion part.

This gives us a vector of parameters before the event. We could do the same for the three days after the event, but then we have the problem that is described before: a small change in option prices might lead to a large change in calibrated parameters. Therefore we perform the estimation after the event using the regularization method. The estimate from before the event is used as prior distribution. Relative entropy is calculated in Appendix B.

The parameter $\alpha$ is chosen as follows: first we perform an unregularized estimation on data after the event and denote the estimation error by err ${ }^{\text {unreg }}$. After that we perform the regularized estimation and we choose $\alpha$ as high as possible, but with the restriction that err $^{r e g} \leq 1.25 * e r r^{r e g}$. In words, we are willing to give up at most $25 \%$ accuracy in order to find a solution closer to the prior. Our prior equals the estimation before the event. This is to make sure that a large change in implied distributions is also really caused by a large change in option prices.

We illustrate how this works by an example. After calibrating the Kou model without regularization on data around 9-12-2015 (Announcement of sixth LTRO), we obtain the following parameters: $\theta^{\text {Kou }, B}=\left(\lambda^{*}, \eta_{2}^{*}\right)=(0.23,12.17)$ (Before) and $\theta^{K o u, A}=\left(\lambda^{*}, \eta_{2}^{*}\right)=(0.46,18.97)$ (After). We can translate this to a jump probability and a jump size. The probability of a jump within one year, $P($ Jump $)=1-e^{-\lambda^{*}}$ and the expected jump size, $E($ Jump $)=\frac{-1}{\eta_{2}+1}$. Then $\theta^{\text {Kou }, B}=(P($ Jump $), E(J u m p))=(20.2 \%,-7.6 \%)$ and $\theta^{\text {Kou, } A}=(P($ Jump $), E($ Jump $))=$ $(36.9 \%,-5.0 \%)$. This looks like there has been quite an effect due to the event. However, after regularization of the estimation after the event, we find out without losing more than $25 \%$ accuracy that we can select $\theta^{K o u, A}=\left(\lambda^{*}, \eta_{2}^{*}\right)=(0.23,12.17)$, or in terms of jumprisk probability and expected jumpsize: $\theta^{\text {Kou, } A}=(21 \%,-7.6 \%)$ which is almost identical to $\theta^{\text {Kou }, B}$. Therefore, we can conclude that the event had no large effect on the implied distributions.

\subsection{Joint estimation}

The second method we use to find out whether ECB announcements have reduced crash risk of the Euro, is joint estimation. Instead of performing an estimation on data of three days before and after an event separately, we jointly calibrate our parameters on data before and after the

\footnotetext{
${ }^{11}$ We use random search instead of grid search since random search is more efficient (Bergstra \& Bengio, 2012). We use $10^{5}$ random combinations of $\left(\lambda^{*}, \eta_{2}^{*}\right)$ with values between $([0,1],[1,19])$.
} 
event. However, we allow the jump probability to vary. So we actually restrict the jump size to be the same before and after the event.

This method implies that we assume that the ECB's UMP actions can only reduce the probability of a crash, not the size. With this restriction we give up some flexibility but solve the identification problem between the arrival rate and the jump size.

Moreover, we are able to test whether there has been a significant change in jump probability. Denote by $\lambda^{* B}$ and $\lambda^{* A}$ the arrival rate respectively before and after the event. We test the following hypothesis:

$$
H_{0}: \lambda^{* B}=\lambda^{* A} \text { vs. } H_{1}: \lambda^{* B} \neq \lambda^{* A}
$$

In order to test the hypothesis, we specify two models. The model described above is called the unrestricted model. In the unrestricted model, the jump size is still restricted to be the same over both periods but the jump probability is unrestricted. Let $t=1,2,3$ be the three trading days before the event and $t=4,5,6$ the three trading days after the event. Then the weighted sum of squared residuals for the unrestricted model equals:

$$
\begin{aligned}
& S S R^{u r}=\min _{\lambda^{* B}, \lambda^{* A}, \eta_{2}^{*}} \sum_{i=1}^{3} \sum_{j=1}^{7}\left\{\sum _ { t = 1 } ^ { 3 } \omega _ { i , j , t } \left[C^{\text {Kou }}\left(S_{t}, \tau_{i}, K_{i, j, t} \mid\left(\sigma, \lambda^{* B}, \eta_{2}^{*}\right)\right)\right.\right. \\
& \left.\left.-C^{*}\left(S_{t}, \tau_{i}, K_{i, j, t}\right)\right]^{2}+\sum_{t=4}^{6} \omega_{i, j, t}\left[C^{\text {Kou }}\left(S_{t}, \tau_{i}, K_{i, j, t} \mid\left(\sigma, \lambda^{* A}, \eta_{2}^{*}\right)\right)-C^{*}\left(S_{t}, \tau_{i}, K_{i, j, t}\right)\right]^{2}\right\} \\
& \text { with } \sum_{i=1}^{3} \sum_{j=1}^{7} \sum_{t=1}^{6} \omega_{i, j, t}=1
\end{aligned}
$$

The restricted model represents the null hypothesis. We perform one joint estimation on the data before and after the event. The weighted sum of squared residuals of this model equals:

$$
\begin{aligned}
& S S R^{r}=\min _{\lambda^{*}, \eta_{2}^{*}} \sum_{i=1}^{3} \sum_{j=1}^{7} \sum_{t=1}^{6} \omega_{i, j, t}\left[C^{K o u}\left(S_{t}, \tau_{i}, K_{i, j, t} \mid\left(\sigma, \lambda^{*}, \eta_{2}^{*}\right)\right)-C^{*}\left(S_{t}, \tau_{i}, K_{i, j, t}\right)\right]^{2} \\
& \text { with } \sum_{i=1}^{3} \sum_{j=1}^{7} \sum_{t=1}^{6} \omega_{i, j, t}=1
\end{aligned}
$$

Then we can test whether we can reject the null hypothesis using an F-test with the following F-statistic:

$$
F=\frac{\left(S S R^{u r}-S S R^{r}\right) / 1}{S S R^{r} /(126-3)}
$$

Here 1 is the difference in degrees of freedom between the restricted and unrestricted model, 126 is the number of observations that is used per estimation and 3 is the number of parameters of the unrestricted model. The null hypothesis is rejected if $F>3.92$ (Significance level $=5 \%$ ) or if $F>6.85$ (Significance level $=1 \%$ ).

\section{Results}

\subsection{Risk reversals}

\subsubsection{Descriptive analysis}

Table 1 lists all the UMP announcements we test in the event regression analysis, along with a short description of the event. The Table shows the net change in the 10 delta option volatility 
over a the event-window surrounding the announcement dates of unconventional policies.

Although we observe an increase in the risk reversals in most cases, the effect of the announcements on the risk reversals is far from uniform. Nonetheless there are some takeaways. For the SMP, LTRO, CBPP, ABSPP, OMT and CSPP the initial announcements caused the risk reversal to decrease (become more negative), which can be interpreted as a increase in perceived tail risk. This can be a signal markets where underwhelmed by the announcement, or simply did not believe the programs would reduce euro break-up risk. The announcement of the PSPP LTRO and NIRP program shows increasing risk reversals, i.e. less break-up risk. Also when the full implications of the OMT where revealed we observe markets priced in lower crash risk.

The most striking observation is made in figure 3 which shows the risk measure for the 1month horizon surrounding the announcements for the OMT program. It immediately becomes clear that Draghi's 'whatever it takes' did not deliver upon market expectations. Tail risk only slightly decreased in the run-up to the event, but increased substantially afterwards. Seemingly investors where either disappointed by the speech, or found the statement contained too little information to scale down their hedging. This view changed when Draghi announced the ECB would join forces with governments to buy sovereign debt. Figure 3 shows a jump in tail-risk in the days after Draghi's statement (also reflected by the sizable decrease in tail-risk for these events in Table 1). Definitive relief came in September 2012, when Draghi announced more details and implications of the OMT. In the days following this announcement the risk reversal moved close to zero, signaling a nearly equal probability of the euro moving up or down.

Figure 3: Risk reversals surrounding the OMT program announcements

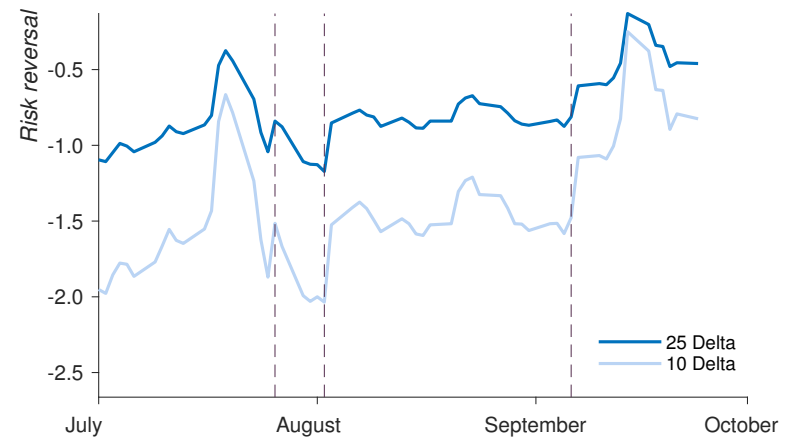

Note: Figure 3 displays the 10 and 25 delta risk reversal derived from 1-month options form July 2012 until October 2011. The dotted lines represent the announcement days (from left to right) of the first, second and third OMT announcement as defined in table 1.

Figure 4 shows the development in the risk reversals over time for some of the other key ECB UMP announcements. The SMP programs caused markets to downplay tail-risk slightly, but the upward move for the SMP announcement was very short-lived. The LTRO announcement actually led to an increase in perceived crash-risk, although that increase was once again shortlived. After this short-lived uptick in perceived crash-risk, the gradual slide downwards (lower risk) continued. We already discussed the OMT, but the lower left panel shows again that announcing the details of the OMT significantly lowered perceived crash-risks, although we saw before that the announcement itself did not have such an impact. The last panel in 4 at the lower-right shows the impact of a bundle of measures announced that day: in the first of a series of announcements on the 4th of June 2014, the ECB both decided to conduct a TLTRO and announced its deposit facility rate would be lowered to -0.1 by the 11 th of June. In later 
Table 1: Net change in risk reversal during the event window $(\mathrm{T}=3)$.

\begin{tabular}{|c|c|c|c|}
\hline Program & Date & & $\Delta 10 \delta R R$ \\
\hline SMP & $\begin{array}{l}9-5-2010 \\
14-5-2010 \\
7-8-2011\end{array}$ & $\begin{array}{l}\text { Launch of the SMP } \\
\text { ECB publishes the SMP details } \\
\text { Re-launch of the SMP }\end{array}$ & $\begin{array}{l}-1.613 \\
0.528 \\
-1.223\end{array}$ \\
\hline LTRO & $8-12-2011$ & Announcement of two LTROs & -0.858 \\
\hline TLTRO & $\begin{array}{l}5-6-2014 \\
16-9-2014 \\
9-12-2014 \\
17-3-2015 \\
16-6-2015 \\
22-9-2015 \\
9-12-2015 \\
22-3-2016\end{array}$ & $\begin{array}{l}\text { ECB decides to conduct a series of TLTROs } \\
\text { Announcement of the first LTRO } \\
\text { Announcement of the second LTRO } \\
\text { Announcement of the third LTRO } \\
\text { Announcement of the fourth LTRO } \\
\text { Announcement of the fifth LTRO } \\
\text { Announcement of the sixth LTRO } \\
\text { Announcement of the seventh LTRO }\end{array}$ & $\begin{array}{l}0.135 \\
0.210 \\
0.183 \\
0.260 \\
-1.255 \\
-0.088 \\
0.195 \\
-0.628\end{array}$ \\
\hline CBPP & $\begin{array}{l}4-6-2009 \\
10-6-2011 \\
4-9-2014\end{array}$ & $\begin{array}{l}\text { Start of the first CBPP } \\
\text { Start of the Second CBPP } \\
\text { Start of the third CBPP }\end{array}$ & $\begin{array}{l}-1.845 \\
0.765 \\
-0.243\end{array}$ \\
\hline ABSPP & $10-6-2011$ & Start of the ABPP & -0.785 \\
\hline OMT & $\begin{array}{l}26-7-2012 \\
2-8-2012 \\
6-9-2012\end{array}$ & $\begin{array}{l}\text { Draghi:"whatever it takes" } \\
\text { Technical features of OMT } \\
\text { Extension of SMP and details of OMT }\end{array}$ & $\begin{array}{l}-0.433 \\
0.438 \\
0.468\end{array}$ \\
\hline NIRP & $\begin{array}{l}5-6-2014 \\
4-9-2014 \\
12-3-2015 \\
10-3-2016\end{array}$ & $\begin{array}{l}\text { DFR below zero }(-0.01) \\
\text { DFR to }-0.02 \\
\text { DFR to }-0.03 \\
\text { DFR to }-0.04\end{array}$ & $\begin{array}{l}0.135 \\
-0.243 \\
-0.065 \\
-0.098\end{array}$ \\
\hline PSPP & $\begin{array}{l}22-1-2015 \\
2-2-2015\end{array}$ & $\begin{array}{l}\text { Announcement of PSPP } \\
\text { Details of the PSPP }\end{array}$ & $\begin{array}{l}0.403 \\
0.555\end{array}$ \\
\hline CSPP & $\begin{array}{l}10-3-2016 \\
21-4-2016\end{array}$ & $\begin{array}{l}\text { Announcement of the CSPP } \\
\text { Further details on the CSPP }\end{array}$ & $\begin{array}{l}-0.098 \\
-0.005\end{array}$ \\
\hline
\end{tabular}

Note: Table 1 summarizes the net changes in the crash probabilities in the event-window for all UMP announcements. $\Delta$ reflects the net change in the risk reversal over the event-window. 
Figure 4: Risk reversals surrounding key events in the sample

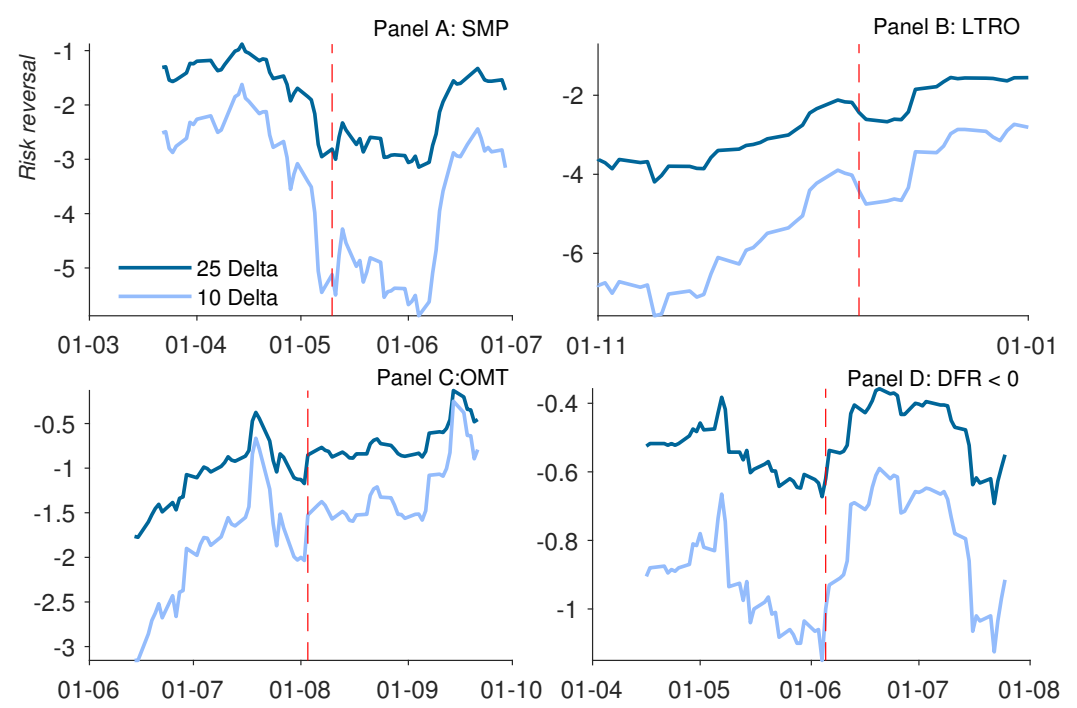

Note: Figure 4 shows the 10 and 25 delta risk reversal derived from options with a 1-month maturity surrounding some key ECB announcements. Panel A shows the risk reversal surrounding the announcement of the first SMP program on 9-5-2010. Panel B shows the announcement of the first TLTRO on the 8th of december 2011. Panel C shows the risk reversal when the implications of the OMT where announced on the 2nd of August 2012. Finally Panel D shows the 10bps Deposit Facility Rate hike to -0.1 on July 5, 2014.

announcements, the rate was lowered to -0.4. Panel D in Figure 4 shows a clear direction upwards for the risk reversals, i.e. the risk of a crash decreased substantially after the June 4 announcements.

\subsubsection{Event regressions on the RR measure}

Table 2 presents the results for UMP announcements on the Eurodollar option risk reversals for different maturities. The coefficient $\theta$ is the regression coefficient of the UMP announcement dummies on the risk measure (the change in the $10 \delta R R$ ).

As can be expected from the data described in Table 1, we do not find any significant reduction in tail-risk perceptions for the options with a near-term maturity. The data showed a somewhat clearer direction for the initial announcements, but do not show uniform behavior in the other announcement taken into consideration. Table 2 shows there is no jointly significant effect for all UMP announcements combined (column (1)). The coefficient is negative, i.e. the risk reversal on average actually decreased, but not significantly so. An objection could be that we combine a wide variety of policy measures, not all of which had the same objective. As discussed earlier, the ECB itself distinguishes measures aimed at influencing the Monetary Stance (MS), broadly speaking measures aimed at changing relative asset supplies, from measures intended specifically to improve the Monetary Transmission Channel (MTC). Appendix A matches specific programs to mone or the other objective ${ }^{12}$. When we make a distinction between the MTC programs - which were mainly focused on bank capital requirements and cost of funding, there is, on

\footnotetext{
${ }^{12}$ We thank Christiaan Pattipeilohy (DNB) for introducing us to the ECB views on program objectives and the associated classification in MS and MTC categories.
} 
Table 2: UMP announcements and changes in risk reversals

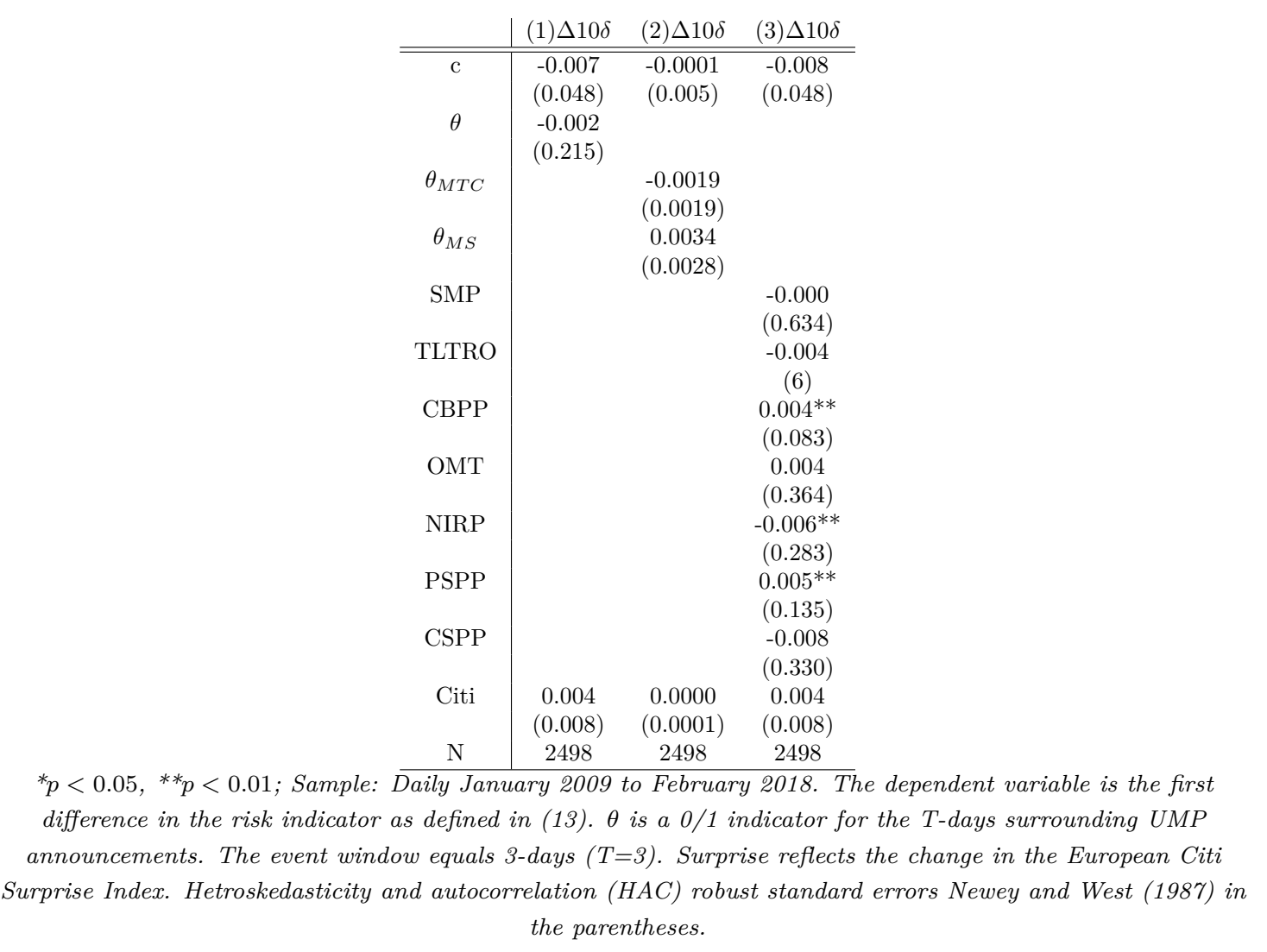

average, a stronger effect for the MS measures and the latter has the "right" sign, but neither is significant. This changes when we examine the individual announcements. The CBPP and PSPP have a positive and significant impact in the tail-risk perception as measured by the risk reversals. For the interest rate announcements we find a negative and significant coefficient. The decisions on the interest rate did not shift the risk reversal in the direction one would expect. However it should be noted the risk reversal only captures the relative position of two data points on the volatility curve and therefore a shift in the risk reversal might be hard to interpret. In particular, if the increase in left-skew occurs at the same time that overall volatility declines, it actually cannot be excluded that the crash probability declined in spite of the increased skew. We therefore turn to more direct ways of measuring crash probabilities.

\subsection{Tail risk measures based on the full implied distribution}

Whereas the first method provides a clear and intuitive way of measuring the perception of tail risk in financial markets via risk reversals, our second - more precise - measure exploits more granular information to construct the entire option-implied densities. This second method relies on risk neutral probability distributions (RNPD) to back out asset price distributions and subsequently estimate the perceived crash likelihood (i.e. the left-tail of the distribution). The area under the RNPD is estimated for all days in the sample resulting in a daily time-series 
Table 3: Net change in crash probabilities during the event window $(\mathrm{T}=3)$.

\begin{tabular}{ll|l|l} 
Program & & Date & $\Delta F(x)(\%)$ \\
\hline \hline SMP & launch of the SMP & $9-5-2010$ & 1.942 \\
& ECB publishes the SMP details & $14-5-2010$ & 0.037 \\
& Re-launch of the SMP & $7-8-2011$ & 1.473 \\
\hline LTRO & Announcement of two LTROs & $8-12-2011$ & 0.299 \\
\hline TLTRO & Announcement of the first TLTROs & $5-6-2014$ & 0.000 \\
& Announcement of the second TLTRO & $16-9-2014$ & 0.000 \\
& Announcement of the third TLTRO & $9-12-2014$ & -0.001 \\
& Announcement of the fourth TLTRO & $17-3-2015$ & 0.005 \\
& Announcement of the fifth TLTRO & $16-9-2014$ & -0.245 \\
& Announcement of the sixth TLTRO & $22-9-2015$ & -0.267 \\
& Announcement of the seventh TLTRO & $9-12-2015$ & 0.026 \\
& Announcement of the eighth TLTRO & $22-3-2016$ & -0.007 \\
\hline CBPP & Start of the first CBPP & $4-6-2009$ & 0.203 \\
& Start of the Second CBPP & $6-10-2011$ & -2.036 \\
& Start of the third CBPP & $4-9-2014$ & 0.000 \\
\hline ABSPP & Start of the ABPP & $6-10-2011$ & 1.578 \\
\hline OMT & Draghi:"whatever it takes" & $29-7-2012$ & 0.010 \\
& Technical features of OMT & $2-8-2012$ & -0.061 \\
& Extension of SMP and details of OMT & $6-9-2012$ & -0.114 \\
\hline NIRP & DFR below zero (-0,01) & $5-6-2014$ & 0.000 \\
& DFR to -0,02 & $4-9-2014$ & 0.000 \\
& DFR to -0,03 & $3-12-2015$ & -0.383 \\
& DFR to -0,04 & $10-3-2016$ & -0.133 \\
\hline PSPP & Announcement of PSPP & $22-1-2015$ & 0.104 \\
& Details of the PSPP & $2-2-2015$ & -0.349 \\
\hline CSPP & Announcement of the CSPP & $10-3-2016$ & -0.133 \\
& Further details on the CSPP & $21-4-2016$ & -0.001 \\
\hline
\end{tabular}

Note: Table 3 summarizes the net changes in the RNPD crash probabilities $(\geq 10 \%)$ in the event-window for all UMP announcements. $\Delta$ reflects the net change in the crash-probability.

capturing the risk of a crash embedded in the options. This measure then serves as input in event study regressions later on.

\subsubsection{Crash probabilities}

In Table 3 we list once again all the UMP announcements that will be tested in the regression analysis, with the corresponding change in crash probabilities. The data represents the net change in the crash probability, as the probability of a crash bigger than $10 \%$ over a one-month horizon is typically very small, we also find small reductions in crash risk. For the OMT we find confirmation on the ineffectiveness of the 'whatever it takes' speech itself or rather the total lack of reaction of the perceived likelihood of a crash at that date, but also of a strong risk reduction effect of the announcements of the technical details later on. For the first SMP announcement we again find the biggest increase in crash risk $(+1.942 \%)$, the second and third SMP announcement also did not manage to reduce crash-risk.

To gain some intuition for the data, figure 5 plots the implied distributions around some of the events we study, i.e. the initial announcements for the SMP, LTRO, OMT and NIRP programs. The sometimes rough shape of the RNPD reflects the characteristics of the used cubic spline, on which we do not impose any shape. For most programs we find the distributions shifted downwards after the all UMP announcements except - again - for 'whatever it takes'.A shift downwards reflects a lower spot price for the Euro, but does not have to reflect lower crashprobabilities. 
Figure 5: Option implied distributions from 1-month options
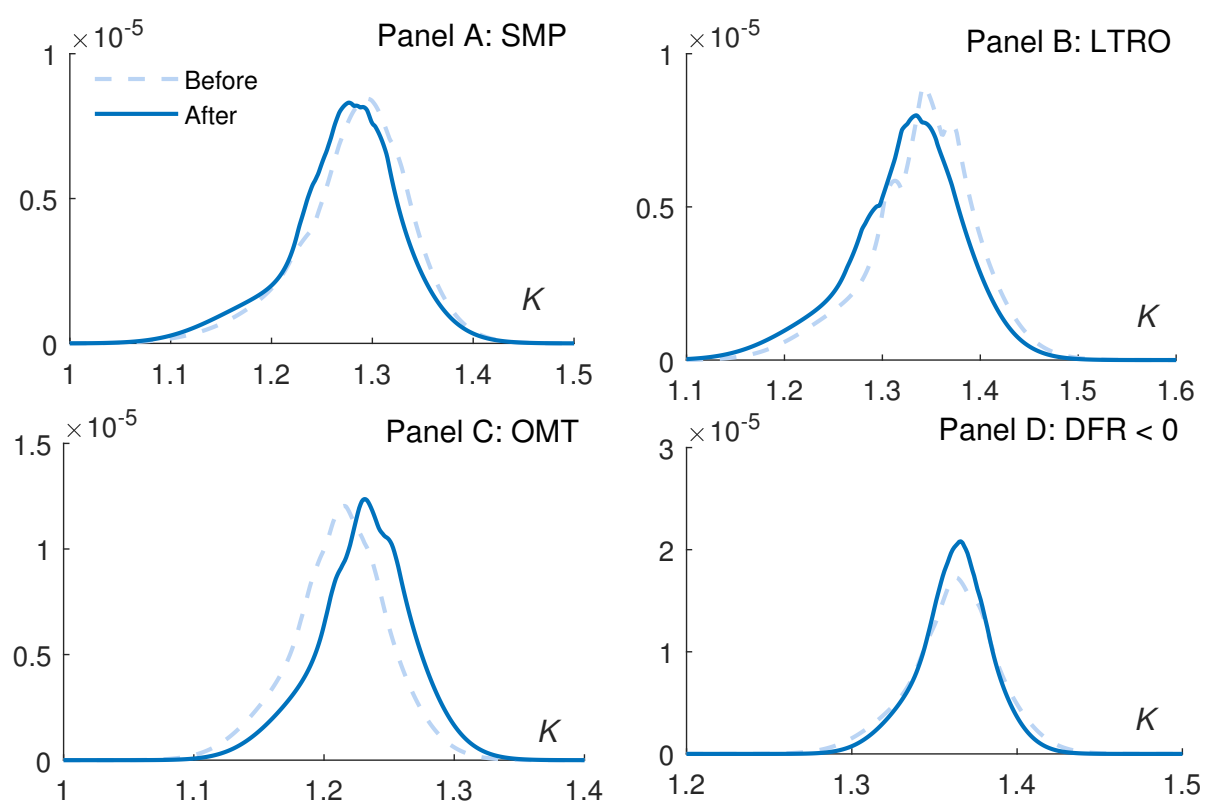

Note: Figure 5 shows risk-neutral probability densities one day prior to the event, and 5 businesses after. Panel A shows the announcement of the SMP program on 9-5-2010, Panel B shows the announcement of the first two LTRO programs on the 8th of december 2011, Panel C shows the RNPD surrounding Draghi's 'Whatever it takes' speech Draghi (2012), Panel D show the RNPD before and after the ECB decision to lower the deposit rate facility (DFR) below zero. $y$-axis reflects the density in percentage points, $\mathrm{x}$-axis the strike price K. RNPD derived from options with a maturity of one month.

Figure 6: Time series of a $10 \%$ and $20 \%$ crash

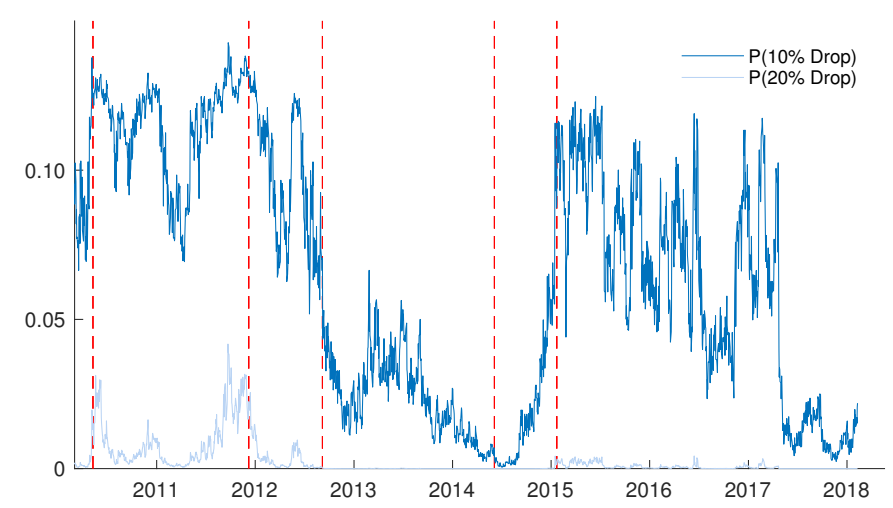

Note: Figure 6 shows the crash probabilities defined as a drop of $10 \%$ and $20 \%$ derived from the RNPR based on 1-month options. y-axis in percentage points, x-axis in years. Red dotted lines represent (form left to right) the first announcement of the SMP, the first announcement of the TLTRO program, Technical features of the

OMT, announcement to lower the DFR below 0 and the announcement of the PSPP. 
From the distributions shown in Figure 5 we can calculate the probability of a drop in the exchange rate in the coming month with 10 percent or more and 20 percent or more. Figure 6 shows this (left) tail probability in a time series. Both the perceived probability of a 10 percent and 20 percent drop spiked just before the announcement of the SMP and stayed high due to an unfolding sovereign debt crisis that threatened the euro. When examining the probabilities surrounding the LTRO in 2011 we find they decreased just after the announcement, with the drop in the probability of a $10 \%$ decline being the most notable. The probabilities further declined after the announcement of the OMT late 2012. Against the background of rising deflation risks late 2014 we also find the crash probability increased substantially, where the PSPP only seems to manage a short-lived decrease after the announcement. Perceived crash risk also spiked in April 2017, around the French elections. It should be noted though, that the probability of a 20 percent decrease never really went up after 2012. It seems that, at least for the LTRO, OMT and NIRP announcement the risk reduction is sustained. For the LTRO the observation is different as is shown by Panel A. Although there is a reduction in crash risk observable, it is far less pronounced than is the case for the OMT and NIRP announcement.

\subsubsection{Event regressions on Tail Risk calculations}

Table 4 shows the results for the base-line regression (13), the $10 \%$ drop on the dummy setup and the Citi Surprise Index. When we set the dummy to one for every event in the sample we find the coefficient is negative but still not significant. It indicates market participants revised down the crash risk down by 2 percent on average over the event window. Table 4 again differentiates between the announcements made on Quantitative Easing measures aiming directly at relative asset supplies, or, in ECB-speak, on influencing the Monetary Stance (MS) from those aimed directly at the monetary transmission Channel (MTC); see Appendix A for a detailed list matching programs to one or the other objective. The results show these programs where not followed by a significant decline in crash risk. On the contrary we now find bigger crash risk reductions for the remaining programs, with an average reduction of $3 \%$ in the perceived crash risk. When we further differentiate between the dummies and make separate dummy variables for all UMP programs we find similar results. For the OMT and NIRP announcements we find a significant reduction in crash risk. The NIRP announcements seem to yield the most $(-11 \%)$ effect on risk perceptions, followed by the OMT(-5\%). The combined LTRO and TLTRO dummy proves insignificant. The same holds for both asset purchase programs, the CSPP and PSPP did not cause a uniform, significant reduction in perceived crash risk. For the SMP dummy we also find significant results but with a positive coefficient. This should not come as a surprise given the plots we made earlier (Figure 5 and 6) we clearly observed an increase in implied crash risk. It should be noted these results are somewhat different than those following from the risk reversals. We only find a coefficient with the same sign for the NIRP. Apparently the more granular data provide us information the risk reversal was unable to pin down.

\subsection{Crash risk measures derived from the mixed jump-diffusion option pricing model}

The results of the estimation procedures are presented in Table 5 and Table 6 for respectively the regularization method and the joint estimation method. Let us first consider the results obtained using the regularization method. Four events reduced the jump risk implied in option prices with at least $25 \%$. The largest reduction is after the announcement where the ECB provided the detailed technical features corresponding to the OMT program. The jump risk also decreased significantly after the press conference one month earlier where Draghi answered questions about 
Table 4: UMP Announcements and change in crash probabilities

\begin{tabular}{c|ccc} 
& $(1) \Delta F_{10 d}(x)$ & $(2) \Delta F_{10 d}(x)$ & $(3) \Delta F_{10 d}(x)$ \\
\hline \hline $\mathrm{c}$ & 0.002 & 0.005 & 0.003 \\
& $(0.013)$ & $(0.013)$ & $(0.013)$ \\
& -0.189 & & \\
$\theta_{M T C}$ & $(0.127)$ & -0.0271 & \\
& & $(0.1097)$ & \\
$\theta_{M S}$ & & $-0.170^{* *}$ & \\
& & $(0.0589)$ & $0.204^{* *}$ \\
SMP & & & $(0.061)$ \\
& & & -0.130 \\
TLTRO & & & $0.168)$ \\
& & & 0.390 \\
CBPP & & & $(0.314)$ \\
& & & $-0.470^{* *}$ \\
OMT & & & $0.174)$ \\
& & & $-1.111^{*}$ \\
NIRP & & & $(0.500)$ \\
& & & -0.063 \\
PSPP & & & $0.057)$ \\
& & & 0.115 \\
CSPP & & & $0.382)$ \\
& & & -0.001 \\
Citi & -0.001 & -0.0004 & $0.002)$ \\
& $(0.001)$ & $(0.0016)$ & 2498 \\
N & 2498 & 2498 &
\end{tabular}

${ }^{*} p<0.05{ }^{* *} p<0.01$; Sample: Daily January 2009 to February 2018. The dependent variable is the 1-day log change in the risk indicator for options with a maturity of 1 month. $\theta$ is a 0/1 indicator for the T-days surrounding UMP announcements. The eventwindow equals 3-days (T=3). Surprise reflects the change in the European Citi Surprise Index. Heteroskedasticity and autocorrelation (HAC) Newey and West (1987) robust standard errors in the parentheses. 
the specifics of the program. An interesting observation is that the famous 'Whatever it takes'speech itself had no effect on the option prices. The announcement of the CSPP did reduce jump risk in spite of it being a mere announcement without specific details. However, at the same day, the ECB also decided to lower the Deposit Facility Rate (DFR) to $-0.4 \%$. Here the further details on the CSPP do not have much effect, but the announcement combined with the lower DFR did have an impact. This is contrary to the time pattern of responses to the OMT speech. Apparently the OMT announcement was too vague for investors, where the CSPP announcement did provide enough information about the program for the later announcement of specification details not to have a measurable impact on jump risk. Lastly, the lowering of the DFR to $-0.3 \%$ at 3-12-2015 had a large impact on jump risk. At this day, Draghi gave a press conference, where the ECB additional to the lower deposit rate also announced several monetary policy decisions to maintain price stability. The asset purchasing program was extended, principal payments on purchased securities were announced to be reinvested, the public sector purchasing program was extended to local and regional goverments and the main refinancing operations were extended. Therefore we can only say that the total package reduced the risk, but not whether specifically lowering the interest rate had an effect. One unexpected outcome is that the announcement of the seventh LTRO has increased jump risk with approximately 30\%. However, if we look at the estimated jump probabilities we see that the estimation yields a very small probability on a jump. Therefore, it might be that a small change in option prices can already lead to a change in jump probability from $0.9 \%$ to $1.1 \%$. Also the announcement of the fifth LTRO seems to have slightly increased the crash probability. 







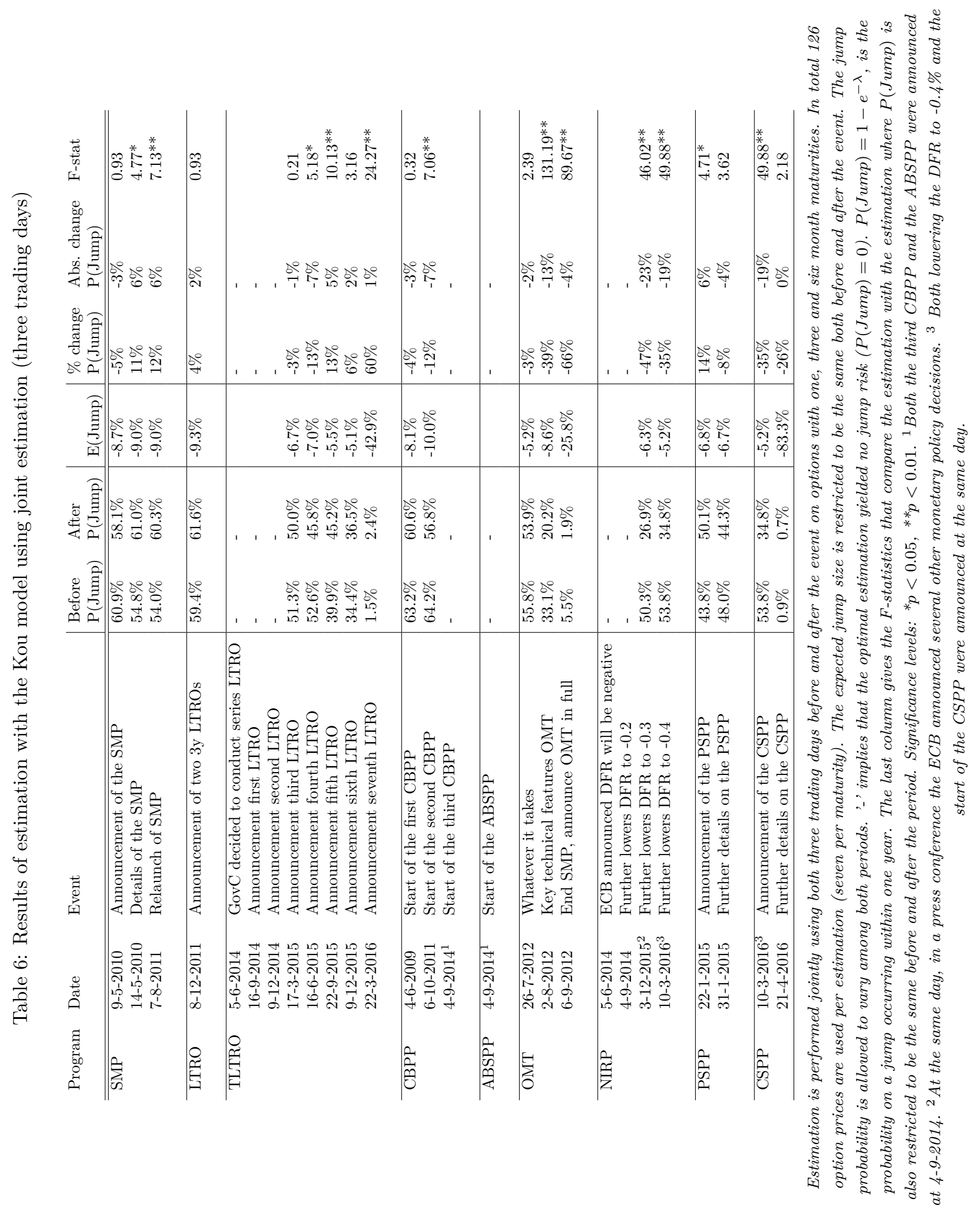


Next let us take a look at the significance of these changes in jump probabilities. To that end we combine the pre- and post-event data and estimate the change in jump risk directly. The same four events that had a large effect for the regularization method are now highly significant using the joint estimation method. Here, we have actually four indicators that capture the total change in jump risk. First of all, we have to take into account the expected jump size. A reduction of jump risk when the expected crash is $20 \%$ is more important than when the expected crash would be $5 \%$. Moreover, we calculate both the percentage and absolute change in jump size. Last and maybe even most important, the F-statistic captures the significance of the change in jump probability.

If we consider the F-statistics, the press conference where Draghi answered questions about the key technical features of the OMT has the highest F-statistic. The event is followed by the detailed technical features of the OMT and after that the announcement of the CSPP combined with the lower DFR. The detailed technical OMT features relatively reduced jump risk the most $(-66 \%)$, where the announcement of the lower DFR at 3-12-2015 combined with several other monetary policy decisions reduced jump risk the most in absolute terms $(-23 \%)$. We see again the same pattern in OMT announcements. The 'Whatever it takes' speech was too vague and is therefore insignificant, where the more detailed announcements are highly significant. Furthermore, we also find that the start of the second CBPP (Corporate Bond Purchasing Program) significantly reduces jump risk.

Lastly, we now find that several events significantly increased jump risk. First, the relaunch of the SMP seems to have increased the crash probability. It might be that investors were not convinced of the program. Also two LTRO announcements both significantly increased jump risk at a $1 \%$ significance level. For the LTRO announcement at 22-9-2015 it can be the case that the Fed announcement at 17-9-2015 has influenced the results. At that day, investors expected the FED to increase interest rates, but the FED decided to keep its benchmark rate at 0-0.25\%. This initially led to an increase of the EUR-DOL rate of more than $2 \%$. However, the days after the spot rate slowly decreased again as investors might have overreacted. This event might cause the significant increase of jump risk around the fifth LTRO announcement. Concerning the other announcement, the jump probability increased from $1.5 \%$ to $2.6 \%$ which is still very small.

\subsection{Summing Up}

Table 7 provides an overview of the results coming out of the various approaches. First, although the Risk Reversal numbers seemed suggestive, the event window regressions do not always support the first impressions as significant. Most surprizing is maybe the failure of the OMT to significantly change the risk reversal in that regression. But a more detailed look at the entire distribution nuances that conclusion, a nuance that comes out even stronger in the results obtained with the two variants based on the mixed jump-diffusion model estimation. The initial speech did not have a significant impact on asset markets but when the speech was actually backed up with the specifics of what OMT would entail if employed, there was a strong and favorable market response. The jump risk estimates from the Bates-Kou model do not respond significantly to the speech itself but declined substantially and significantly at the two later dates on which details of the OMT program were announced. Management by speech does not seem to be enough by itself. The announcement of the Corporate Bond Purchasing Program did have a significant although relatively small risk reduction effect and the later filling in of the details did not, but the CSPP was a clear measure from the beginning while the OMT speech did not give any particular infomration on what exactly the ECB would do in crisis time, just that whatever it was would be enough. Market participants apparently wanted to see the details before being impressed. 


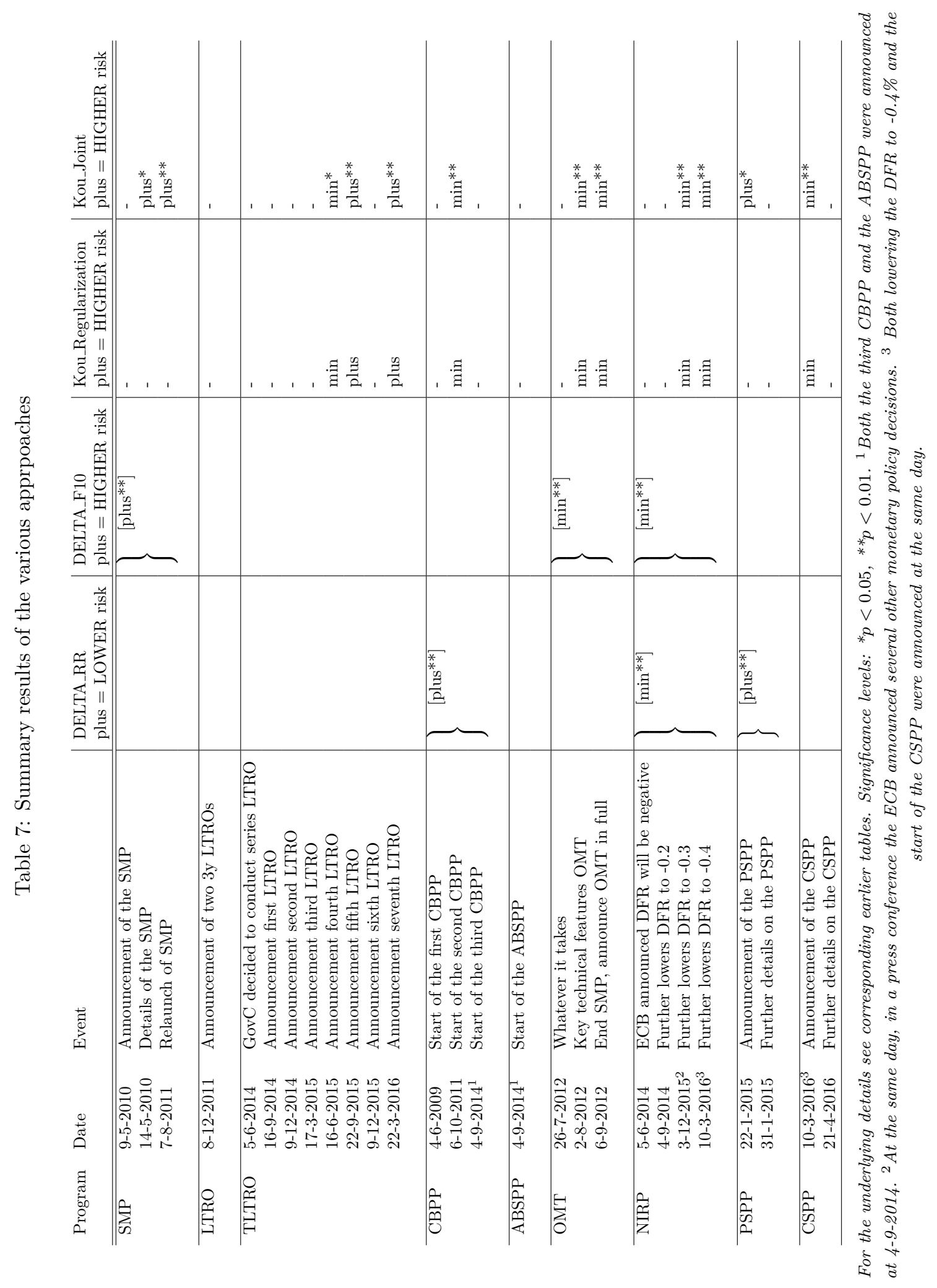


A similar pattern emerged around the announcement of the ECB's flagship program, the Public Sector Securities Purchase Program, whereby the ECB buys up sovereign debt in line with its capital key distribution.

Another strong result emerging from table 7 is that several programs actually seem to have led to higher risk perceptions, possibly signaling panic or ineffectiveness of the measures announced. In particular the SMP program did not really seem to lower risk on the two general measures (RR event window regression and the Kou-Regularization approach) and in the two approaches explicity focusing on tail risk actually led to higher risk perceptions, the opposite of what the purprose of the announcement was. The RR regressions also seem to indicate a perverse increase in risk perceptions for the latest of the ECB's moves into negative interest rate territory, which is somewhat of a surprize because all the three other approaches indicate the opposite, in particular the latest two decreases in the deposit rate lead to significantly lower tail risk perceptions in the other three more focused and information intensive approaches. An explanation for the contradiction may be that at the same time overall volatility declined substantially: although the table suggests the RR decreased (i.e. left skew increased), the overall level of volatility declined significantly at that date: the ATM volatility fell by some $25 \%$ that very day.

A general result that comes out is that the measures focused on influencing the Monetary Transmission Channel (MSC), roughly speaking measures aimed at bank support, did not have a significant impact, a result indicated by all four approaches. The Kou_joint estimates allow for most details and indicate significant but small changes in risk perception, but sometimes up and sometimes down, in line with the general ineffectiveness that comes out of the event window regressions.

Finally, the two flagship programs (CSPP and PSPP) seem to give mixed results. According to both methods based on the jump-diffusion process, the initial announcement of the CSPP is effective (and very significantly so) in reducing risk perceptions, but once the details came out the perception of tail risk did not move anymore. Apparently the announcement was already clear enough about the implications of the Covered Bond Purchasing Program. Concerning the PSPP program, the RR regression does suggest that the overall effect of the PSPP program was to lower tail risk perceptions. However, the other methods give different results. The event window regression based on the risk-neutral distribution and the Kou-Regularization approach find no effects. The Kou_Joint method even suggests that after the announcement of the PSPP the risk perceptions actually went up. Overall, we can conclude that the PSPP program does not seem to be very effective, while the CSPP did reduce risk perceptions

\section{Conclusions}

In this paper we used a series of methods to analyse market perceptions of the risk impact of specific policy measures, simultaneously increasing in data requirements and model specificity. Risk Reversals provide suggestive results, but, while their sparse and relatively straightforward use of readily available data makes them easy to calculate and use them in regression analysis, those very factors may also explain their relative lack of power. Specifically, it is difficult to assess the net impact of for example a decrease in left skew (i.e. a more negative number) if it coincides with a decline in volatility as indicated by a decline in ATM (At The Money) volatility. Using the entire volatility smile/smirk to extract the entire (risk neutral) distribution, while still being non-parametric, does allow for more precise measures of risk and allowed for more powerful tests and more precise results focusing on different descriptive measures of the distribution, like fatness of tailes versus skewness. Risk reversals only capture the skewness, not the kurtosis and the level 
of ATM volatility. Especially when the ATM volatility increases while skewness remains the same the two methods (RR versus RNPD extraction) may give different results. But the numerical procedures used in obtaining the empirical density function unavoidably impose restrictions on the shape of the function that did not allow for the sort of mixed process that allows for precise focus on jump risk probabilities. For this reason we ended up setting up a specific diffusion-jump model, using various methods to estimate its parameters and possible changes in the surrounding policy announcement dates. Using a cascade of methods increasing in complexity proved to be useful since each stage provided information allowing for more precise structuring in the next stage, moving from very general RR all the way to fully analytical derivation and empirical estimation of a mixed diffusion-jump risk model based on exponential densities for the jump risk elements.

A number of general messages emerge from the analysis. First of all, announcing policies in general terms without precisely describing what exactly they entail does not move asset markets or even moves them in the wrong direction. This pattern emerged at the time of the famous OMT speech; risk perceptions only improved once the details were announced one month after the speech; but at the time of the speech itself, risk perceptions actually moved in the wrong direction on several measures, although not significantly so. A similar pattern was revealed by our most powerful approach when analyzing the ECB's flagship program, the PSPP. The initial announcement actually led to higher crash probabilities, a move that was reversed once the details were spelled out ten days later. A second message is that policies aiming at changing relative asset supplies in asset markets do have an impact once they are made clear enough; while measures more generally aiming at easing financing costs of the commercial banks do not. And the third remarkable result is that the SMP program (focusing on providing support for first Greek and later on Italian sovereign debt prices) actually led to higher tail risk perceptions in the Eurodollar market.

\section{References}

Anderson, E., Hansen, L. P., \& Sargent, T. (2000). Robustness, detection and the price of risk. Manuscript, Stanford, 19.

Arteta, C., Kose, M. A., Stocker, M., \& Taskin, T. (2018). Implications of negative interest rate policies: An early assessment. Pacific Economic Review, 23(1), 8-26.

Bates, D. S. (1988). Pricing options under jump-diffusion processes. Citeseer.

Bates, D. S. (1996). Jumps and stochastic volatility: Exchange rate processes implicit in deutsche mark options. The Review of Financial Studies, 9(1), 69-107.

Bergstra, J., \& Bengio, Y. (2012). Random search for hyper-parameter optimization. Journal of Machine Learning Research, 13(Feb), 281-305.

Black, F., \& Scholes, M. (1973). The pricing of options and corporate liabilities. Journal of political economy, $81(3), 637-654$.

Bliss, R. R., \& Panigirtzoglou, N. (2004). Option-implied risk aversion estimates. The journal of finance, 59(1), 407-446.

Breeden, D., \& Litzenberger, R. (1978). Prices of state contingent claims implicit in option prices. Journal of Business, 51, 621-652.

Brunnermeier, M. K. (2009, March). Deciphering the liquidity and credit crunch 2007-2008. Journal of Economic Perspectives, 23(1), 77-100. Retrieved from http://www.aeaweb .org/articles?id=10.1257/jep.23.1.77 doi: 10.1257/jep.23.1.77

Brunnermeier, M. K., Sannikov, Y., et al. (2012). Redistributive monetary policy. In Jackson hole symposium (Vol. 1, pp. 331-384). 
Bu, R., \& Hadri, K. (2007). Estimating option implied risk-neutral densities using spline and hypergeometric functions. The Econometrics Journal, 10(2), 216-244.

Coeure, B. (2017, November). Monetary policy, exchange rates and capital flows. ONLINE ECB. (https://www.ecb.europa.eu/press/key/date/2017/html/ecb.sp171103.en.html)

Cont, R., \& Tankov, P. (2002). Calibration of jump-diffusion option pricing models: a robust non-parametric approach.

De Pooter, M., Rebecca, D., Martin, R. F., \& Pruitt, S. (2015). Cheap talk and thr efficacy of the ecb's securities market programme: Did bond purchases matter?

Draghi, M. (2012). Verbatim of the remarks made by mario draghi. In Speech at the global investment conference, london (Vol. 26).

ECB. (2016). Open market operations. Retrieved from https://www.ecb.eu/mopo/implement/ omo/html/index. en.html

Falagiarda, M., \& Reitz, S. (2015). Announcements of ecb unconventional programs: Implications for the sovereign spreads of stressed euro area countries. Journal of International Money and Finance, 53, 276-295.

Fratzscher, M., Duca, M. L., \& Straub, R. (2014). Ecb unconventional monetary policy actions: Market impact, international spillovers and transmission channels. International Monetary Fund.

Garman, M. B., \& Kohlhagen, S. W. (1983). Foreign currency option values. Journal of international Money and Finance, 2(3), 231-237.

Georgiadis, G., \& Gräb, J. (2016). Global financial market impact of the announcement of the ecb's asset purchase programme. Journal of Financial Stability, 26, 257-265.

Hattori, M., Schrimpf, A., \& Sushko, V. (2016). The effects of quantitative easing on interest rates: Channels and implications for policy. American Economic Journal: Macroeconomics, 8(2), 111â136.

Jorion, P. (1988). On jump processes in the foreign exchange and stock markets. The Review of Financial Studies, 1(4), 427-445.

Kou, S. G. (2002). A jump-diffusion model for option pricing. Management science, 48(8), 1086-1101.

Krishnamurty, A., \& Vissing-Jorgenson, A. (2011). The effects of quantitative easing on interest rates: Channels and implications for policy. BPEA.

Malz, A. (2014). A simple and reliable way to compute optoin-based risk neutral distributions. Staff reports Federal Reserve Bank of New York(677).

Merton, R. C. (1976). Option pricing when underlying stock returns are discontinuous. Journal of financial economics, 3(1-2), 125-144.

Reiswich, D., \& Wystup, U. (2010). A guide to fx options quoting conventions. Journal of Derivatives, $18(2), 58$.

Shinko, D. (1993). Bounds of probability. Risk, 6(33-37).

Shreve, S. E. (2004). Stochastic calculus for finance ii: Continuous-time models (Vol. 11). Springer Science \& Business Media. 


\section{A List of programs with their abbreviations and an indi- cation of their target $^{13}$}

\begin{tabular}{llc} 
Program & & Target \\
ABSPP & Asset backed security purchasing programma & MTC \\
APP & Asset purchasing programme & MS \\
CBPP & Covered bond purchasing programme & MTC \\
CSPP & Corporate sector purchasing programme & MS/MTC \\
CEP & Credit easing package & MTC \\
COLL & Collateral extension & MTC \\
FRTPFA & Fixed rate tenders with full allotment & MTC \\
FWG & Forward guidance & MS \\
LTRO & Long term refinancing operations & MTC \\
MRO & Main refinancing operations & MTC \\
NIRP & Negative interest rate policy & MTC \\
OMT & Outright monetary transactions & MTC \\
PSPP & Public sector purchasing programme & MS \\
SMP & Security markets programme & MTC \\
TLTRO & Targeted long-term refinancing operations & MS/MTC \\
\multicolumn{1}{c}{ MS refers to Monetary Stance, MTC refers to Monetary transmission }
\end{tabular}

\section{B Derivation of relative entropy}

For notational simplicity, we drop the star above the risk-neutral parameters. Then under $\mathcal{Q}$ (risk-neutral measure), $S_{t}$ has the following distribution.

$$
d S_{t}=-\lambda E[V-1] S_{t} d t+\sigma S_{t} d W_{t}+(V-1) S_{t-} d N_{t}
$$

Here $V$ has distribution $f(v)$. Now assume we want to calculate the relative entropy between $\mathcal{Q}$ and a risk-neutral distribution with different parameters, namely $\tilde{\mathcal{Q}}$ with parameters $\tilde{\lambda}$ and pdf $f \tilde{(v)}$. The we can define the Radon Nykodim derivative of $\mathcal{Q}$ with respect to $\mathcal{Q}$ by $Z_{T}=\frac{d \tilde{\mathcal{Q}}}{d \mathcal{Q}}$ where

$$
d Z_{t}=-(\tilde{\lambda}-\lambda) Z_{t} d t-\frac{\tilde{\lambda} \tilde{E}[V-1]-\lambda E[V-1]}{\sigma} d W_{t}+\left(\frac{\tilde{\lambda} f(\tilde{V})}{\lambda f(V)}-1\right) Z_{t-} d N_{t}
$$

and $Z_{0}=1$. Here $\tilde{E}[$.$] is the expectation under the measure \tilde{\mathcal{Q}}$. Using that $d W_{t}=d \tilde{W}_{t}-$ $\frac{\lambda E(V-1)-\tilde{\lambda} \tilde{E}(V-1)}{\sigma}$, we obtain that under $\tilde{Q}$ :

$$
d S_{t}=-\lambda \tilde{E}[V-1] S_{t} d t+\sigma S_{t} d \tilde{W}_{t}+(V-1) S_{t-} d N_{t}
$$

where $\mathrm{V}$ has distribution $f(v)$ and $N_{t}$ has arrival rate $\tilde{\lambda}$ (See Shreve (2004), chapter 11.6.3).

\footnotetext{
${ }^{13}$ We are indebted to Christiaan Pattipeilohy (DNB) for this introduction of ECB language.
} 
Using Ito's lemma for jump processes we get:

$$
\begin{aligned}
d \ln \left(Z_{t}\right) & =-(\tilde{\lambda}-\lambda) d t-\frac{\tilde{\lambda} \tilde{E} V-1]-\lambda E[V-1]}{\sigma} d W_{t} \\
& -\frac{1}{2 \sigma^{2}}(\tilde{\lambda} \tilde{E}(V-1)-\lambda E(V-1))^{2} d t+\ln \left(\frac{\tilde{\lambda} f(\tilde{V})}{\lambda f(V)}\right) d N_{t} \\
& =-(\tilde{\lambda}-\lambda) d t-\frac{\tilde{\lambda} \tilde{E}[V-1]-\lambda E[V-1]}{\sigma} d \tilde{W}_{t} \\
& +\frac{1}{2 \sigma^{2}}(\tilde{\lambda} \tilde{E}[V-1]-\lambda E[V-1])^{2} d t+\ln \left(\frac{\tilde{\lambda} f(\tilde{V})}{\lambda f(V)}\right) d N_{t}
\end{aligned}
$$

Then the relative entropy from $\tilde{\mathcal{Q}}$ to $\mathcal{Q}$ over the interval $[t, t+\Delta]$ equals:

$$
\begin{aligned}
& \mathcal{E}(\tilde{\mathcal{Q}} \mid \mathcal{Q})=\tilde{E}_{t}\left[\ln \left(\frac{Z_{t+\Delta}}{Z_{t}}\right)\right]=\int_{t}^{t+\Delta}-(\tilde{\lambda}-\lambda) d s \\
& +\int_{t}^{t+\Delta} \frac{1}{2 \sigma^{2}}(\tilde{\lambda} \tilde{E}[V-1]-\lambda E[V-1])^{2} d s+\int_{t}^{t+\Delta} \tilde{\lambda} \tilde{E}\left[\ln \left(\frac{\tilde{\lambda} f(\tilde{V})}{\lambda f(V)}\right)\right] d s \\
& =-(\tilde{\lambda}-\lambda) \Delta+\frac{1}{2 \sigma^{2}}(\tilde{\lambda} \tilde{E}[V-1]-\lambda E[V-1])^{2} \Delta+\tilde{\lambda} \tilde{E}\left[\ln \left(\frac{\tilde{\lambda} f(V)}{\lambda f(V)}\right)\right] \Delta
\end{aligned}
$$

The pdf of the jump distribution for the Kou model equals: $f(v)=\eta v^{\eta-1}$. Therefore the relative entropy between $\tilde{\mathcal{Q}}$ and $\mathcal{Q}$ equals:

$$
\begin{aligned}
\frac{\mathcal{E}(\tilde{\mathcal{Q}} \mid \mathcal{Q})}{\Delta} & =-(\tilde{\lambda}-\lambda)+\frac{1}{2 \sigma^{2}}\left(\frac{\lambda}{\eta+1}-\frac{\tilde{\lambda}}{\tilde{\eta}+1}\right)^{2}+\tilde{\lambda} \ln \left(\frac{\tilde{\lambda} \tilde{\eta}}{\lambda \eta}\right)+\tilde{\lambda}(\tilde{\eta}-\eta) \tilde{E}[\ln (V)] \\
& =-(\tilde{\lambda}-\lambda)+\frac{1}{2 \sigma^{2}}\left(\frac{\lambda}{\eta+1}-\frac{\tilde{\lambda}}{\tilde{\eta}+1}\right)^{2}+\tilde{\lambda} \ln \left(\frac{\tilde{\lambda} \tilde{\eta}}{\lambda \eta}\right)+\tilde{\lambda} \frac{\eta-\tilde{\eta}}{\tilde{\eta}}
\end{aligned}
$$

Similarly, for the Merton model we have that $f(v)=\frac{1}{v} \frac{1}{\sqrt{2 \pi} \nu} \exp \left(-\frac{(\ln (v)-\mu)^{2}}{2 \nu^{2}}\right)$. and the relative entropy equals:

$$
\begin{aligned}
\frac{\mathcal{E}(\tilde{\mathcal{Q}} \mid \mathcal{Q})}{\Delta} & =-(\tilde{\lambda}-\lambda)+\frac{1}{2 \sigma^{2}}(\tilde{\lambda} \tilde{\kappa}-\lambda \kappa)^{2}+\tilde{\lambda} \ln \left(\frac{\tilde{\lambda} \nu}{\lambda \tilde{\nu}}\right) \\
& +\tilde{\lambda} \tilde{E}\left[\frac{(\ln (v)-\mu)^{2}}{2 \nu^{2}}-\frac{(\ln (v)-\tilde{\mu})^{2}}{2 \tilde{\nu}^{2}}\right] \\
& =-(\tilde{\lambda}-\lambda)+\frac{1}{2 \sigma^{2}}(\tilde{\lambda} \tilde{\kappa}-\lambda \kappa)^{2}+\tilde{\lambda} \ln \left(\frac{\tilde{\lambda} \nu}{\lambda \tilde{\nu}}\right)+\tilde{\lambda}\left(\frac{\tilde{\nu}^{2}+(\tilde{\mu}-\mu)^{2}}{2 \nu^{2}}-\frac{1}{2}\right)
\end{aligned}
$$

\section{Robustness checks}

In this section, we check whether our results are robust under different assumption. Specifically, we will check whether the choice of the model has much influence on the result. Furthermore, we will look whether the number of trading days around an event on which the estimation is performed influences the results. 


\section{C.1 Merton model}

As a robustness check, we perform the same analysis using the Merton model. Merton (1976) was the first to propose an option-pricing model with jump risk, Jorion (1988) derived the formula for FX options. Recall that the spot rate follows a jump diffusion process with jump size $V-1$.

$$
d S_{t}=(\mu-\lambda E(V-1)) S_{t} d t+\sigma S_{t} d W_{t}+(V-1) S_{t-} d N_{t}
$$

Now assume that $V$ is i.i.d. distributed and follows a log-normal distribution, instead of a doubleexponential distribution: $\ln (V) \sim N\left(\ln (1+\kappa)-\frac{1}{2} \nu^{2}, \nu^{2}\right), E(V)=1+\kappa$. In the Black-Scholes model, the value of an option does not depend on the preference of a representative agent. This is not generally the case for a jump-diffusion model. However, Merton (1976) derived a preferencefree option pricing formula for a jump-diffusion model with the assumption that jump risk is firm-specific and perfectly diversifiable. The result is that jump risk has zero price. Denote the risk-neutral arrival rate by $\lambda^{*}$ and the risk-neutral expected jump size by $\kappa^{*}$. The assumption of Merton implies that diffusion risk is priced the usual way and that jump risk is not priced, such that $\lambda^{*}=\lambda$ and $\kappa^{*}=\kappa$. This assumption might be plausible if we would consider options on specific stocks, but is certainly violated in the case of currency options.

However, Bates (1988) shows that with some additional assumptions, we can also derive a tractable option pricing formula that does price jump risk. Let us assume furthermore that the representative agent has power utility and that wealth of the agent follows a similar jump diffusion process as the underlying. Given these assumptions, we can use the option pricing formula derived by Merton (1976), but with the risk-neutral parameters $\left(\lambda^{*}, \kappa^{*}\right)$ In this case, $(\lambda, \kappa) \neq\left(\lambda^{*}, \kappa^{*}\right)$. For the exact relation between the risk-neutral and the actual parameters, we refer to Bates (1988). However, it does not play a key role in our analysis, since we only estimate the distribution implied in option prices and do not look at the time-series. The price of a European call-option then equals:

$$
\begin{gathered}
C^{\text {Merton }}\left(S, \tau ; K, r_{\$}, r_{€}, \sigma, \lambda^{*}, \kappa^{*}, \nu\right)=e^{-r_{€} \tau} \sum_{n=0}^{\infty} \frac{e^{\lambda^{*}\left(1+\kappa^{*}\right) \tau}\left(\lambda^{*}\left(1+\kappa^{*}\right) \tau\right)^{n}}{n !} * \\
C\left(S, \tau ; K, r_{\$}-r_{€}-\lambda^{*} \kappa^{*}+n \frac{\ln \left(1+\kappa^{*}\right)}{\tau}, \sigma^{2}+n \frac{\nu^{2}}{\tau}\right)
\end{gathered}
$$

Similar to the Kou model, we assume that at most one jump can take place. Therefore we sum only up to and including 1 . The probability of having one jump changes from $e^{\lambda^{*}\left(1+\kappa^{*}\right) \tau}\left(\lambda^{*}(1+\right.$ $\left.\left.\kappa^{*}\right) \tau\right)$ to $1-e^{\lambda^{*}\left(1+\kappa^{*}\right) \tau}$.

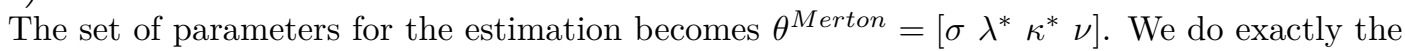
same analysis as we did for the Kou model. To find a starting point for the optimization, we use $10^{6}$ random combinations of $\left(\lambda^{*}, \kappa^{*}, \nu\right)$ with values between $([0,1],[-0.5,-0.05],[0,0.2])$.

The results of the regularization method and the joint estimation method are presented in respectively Table 8 and Table 9 . Let us first consider the regularization method. We see that for most events, the Merton and Kou model give qualitatively similar results. However, for several events the Kou model finds zero change in jump risk after regularization, where the Merton model does find changes even after regularization. This is the case for in total five events, of which four have a change in jump probability of at most $1.5 \%$ in absolute terms. Only the relaunch of the SMP seems to give a slightly different result than in the case of the Kou model

The reason of this difference between the two models is that the Merton model has an additional free parameter, namely the jump volatility. This leads to a lower unregularized error and 
increases the problem of multiple local minima. Therefore it is possible that there is no change in jump risk after regularization in the Kou model, but that there is a change in the Merton model.

If we look at the joint estimation method, it can be seen that the outcomes of both models are comparable. However, the F-statistics are higher for the Merton model. For the Merton model we have in total 12 events that are significant at a $1 \%$ significance level, against 9 events for the Kou model. The same reason as before causes this difference in significance, namely that the unrestricted sum of squared residuals is lower for the Merton model because of an extra free parameter.

However, we can say that our main conclusions remain valid under the Merton model. 


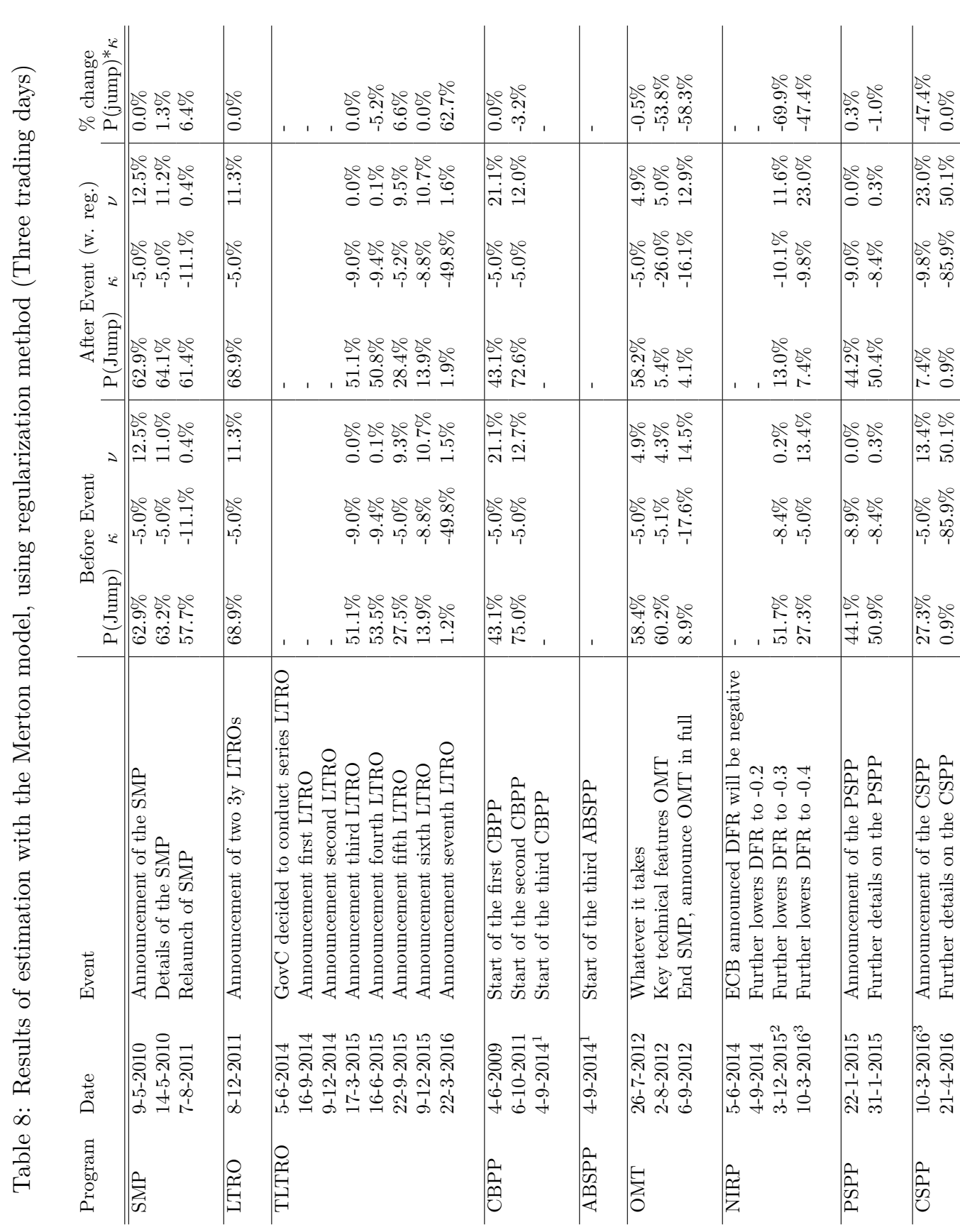

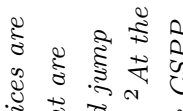

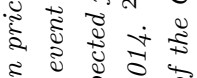

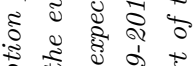

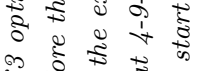

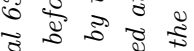

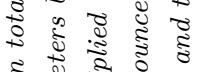

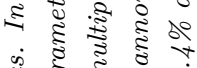
है है

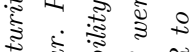
है ซึ क्ष

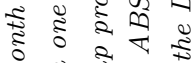

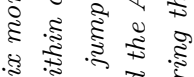
竎 वै हैं है है ( )

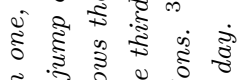

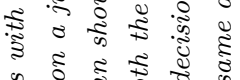
₹ हुำ की के

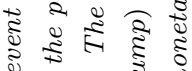

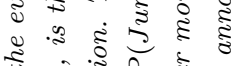
i. \& 1 है है के $\|$ है है है है

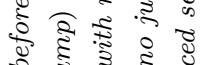

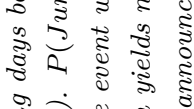

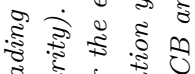

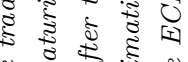

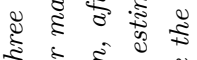

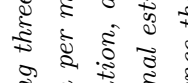

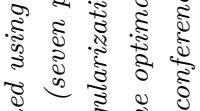

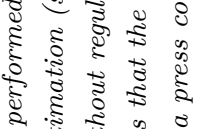

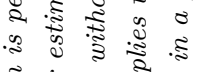
है ₹

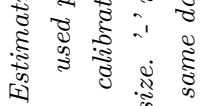




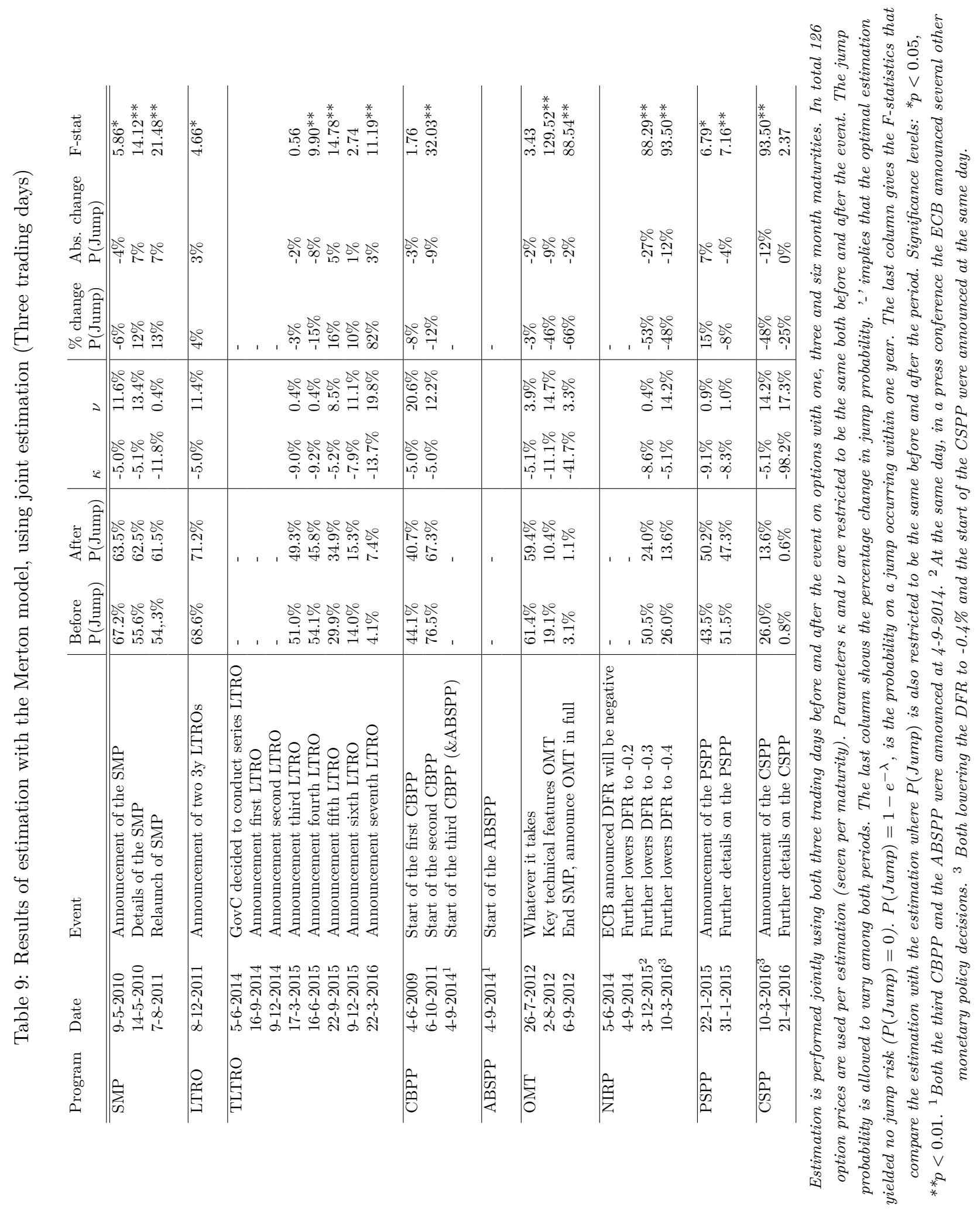




\section{C.2 Number of estimation days}

Lastly, we consider the results using two trading days around an event instead of three. When choosing the number of days around an event, one always has to make the trade off between reducing noise by having more observations and having the possibility of other events influencing the results. Choosing four trading days around an event, might result in a too long period since this implies that the estimation period is around two weeks. Furthermore, only one day before and after gives too little observations. Therefore, we will perform a robustness check with two trading days.

First, we consider the regularization method. We see that the results are very similar, except from one event. The 'Whatever it takes' speech has decreased the jump risk with $-4.7 \%$ if we use two trading days, where it did not do anything for three trading days. However, we still see that the other two OMT announcement have much larger effects.

If we look at the joint calibration method, we see that the $\%$ changes and absolute changes in jump probabilities are quite similar. However, the main difference is in the significance of results. The F-statistic is a function of the number of observations, so if we decrease the sample size than we will overall obtain less significant results. We see that five events become insignificant when we use two trading days that were significant using three trading days. Lastly, we see that surprisingly the 'Whatever it takes' speech becomes significant. So similar to the regularization method, we find that if we use two trading days for estimation, the speech seems to have significantly reduced the jump risk. But again, the magnitude and the F-statistic are much smaller for the speech compared to the other two OMT announcement. So again, our main conclusions remain valid. 


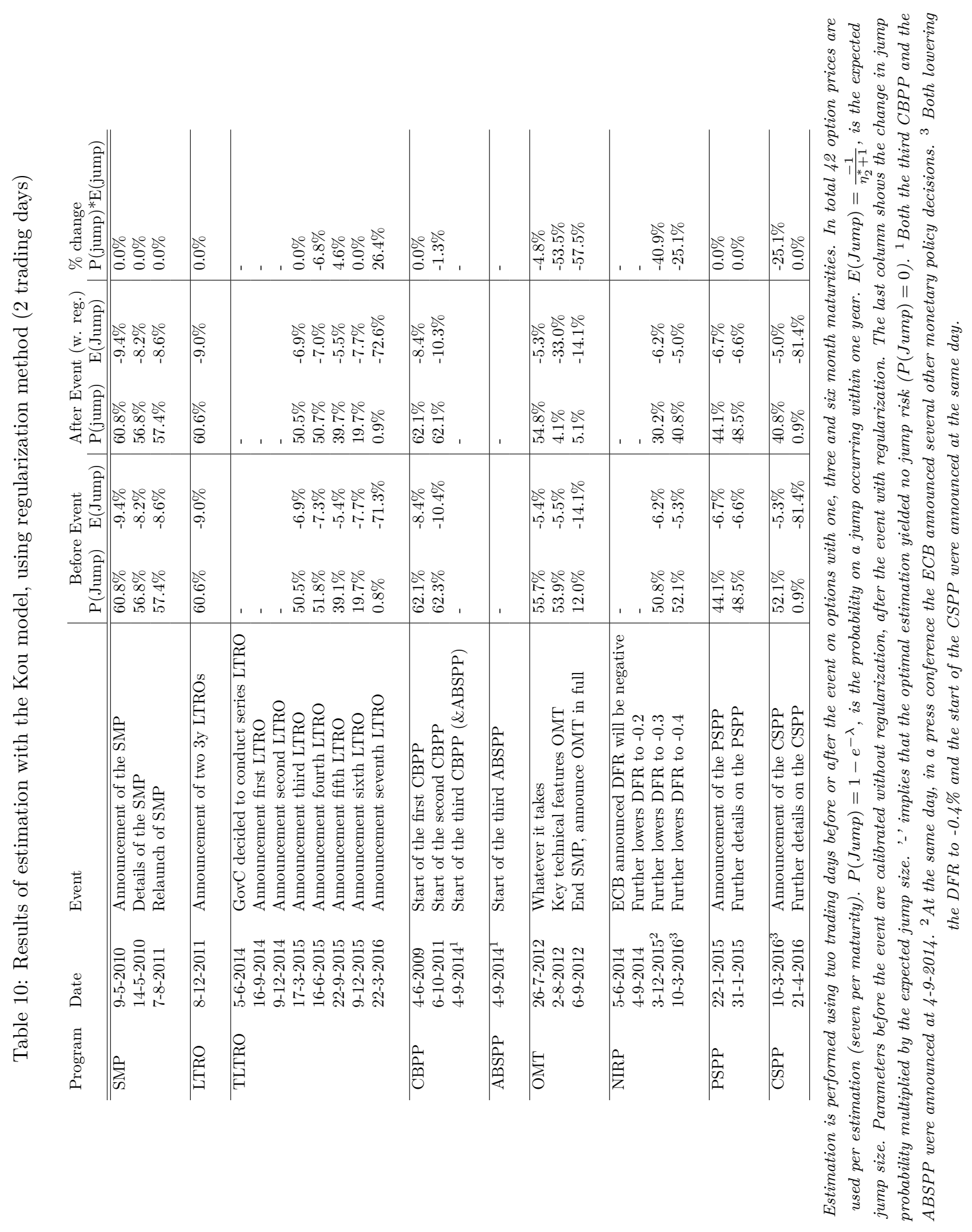




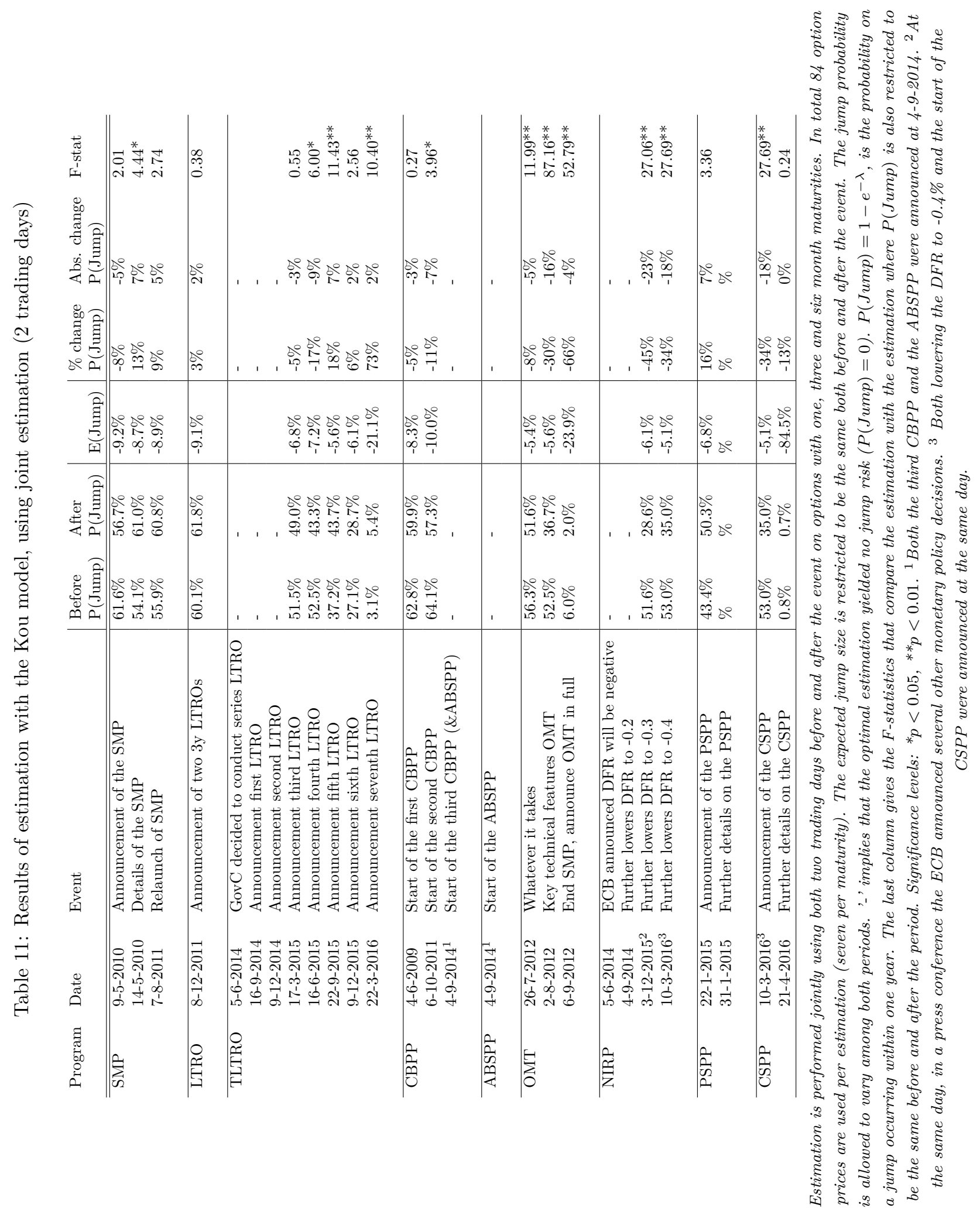

